Silmara Rondon Melo

Educação mediada por tecnologia em fonoaudiologia: uma comparação entre três métodos de aprendizagem sobre o sistema miofuncional orofacial

Tese apresentada à Faculdade de Medicina da Universidade de São Paulo para a obtenção do título de Doutor em Ciências

Programa de Ciências da Reabilitação

Orientadora: Prof. ${ }^{\text {a }}$ Dra. Claudia Regina

Furquim de Andrade

São Paulo 
Dados Internacionais de Catalogação na Publicação (CIP)

Preparada pela Biblioteca da

Faculdade de Medicina da Universidade de São Paulo

Creprodução autorizada pelo autor

Melo, Silmara Rondon

Educação mediada por tecnologia em fonoaudiologia : uma comparação entre três métodos de aprendizagem sobre o sistema miofuncional orofacial / Silmara Rondon Melo. -- São Paulo, 2015.

Tese(doutorado)--Faculdade de Medicina da Universidade de São Paulo. Programa de Ciências de Reabilitação.

Orientadora: Claudia Regina Furquim de Andrade.

Descritores: 1.Fonoaudiologia 2.Anatomia 3.Fisiologia 4.Aprendizagem 5.Instrução por computador 6.Motivação 7.Sistema estomatognático

USP/FM/DBD-187/15 
Dedico esta tese à minha família; especialmente ao meu querido esposo Gerson, companheiro para todas as horas e grande fonte de apoio para meu crescimento espiritual, pessoal e profissional, e à minha filhinha Lia, que em breve virá a este mundo para nos trazer ainda mais bênçãos e alegrias. 
Primeiramente, agradeço ao meu Pai Celestial que tem guiado toda a minha vida para seguir Sua vontade e aberto os caminhos que têm me trazido muitas bênçãos, conhecimento e realização pessoal e profissional.

Ao meu pai Luis Ricardo, que não está mais entre nós, agradeço por tudo que me ensinou e por seu amor. Agradeço por sempre ter me conduzido pelos caminhos que norteariam a ter uma visão correta sobre a importância do estudo de qualidade e de se dedicar a uma profissão digna.

À minha mãe Nidia Mara agradeço por, juntamente com meu pai, ter me concedido o privilégio de nascer em uma ótima família, que sempre me deu muito amor, carinho e me instruiu no verdadeiro evangelho de Jesus Cristo. Agradeço por todo o esforço e amor que demonstrou por toda minha vida para que eu pudesse ter grande bem-estar físico e espiritual, bem como para que eu pudesse estudar e contretizar meus sonhos e objetivos profissionais com alegria e sucesso.

À minha irmã Andressa agradeço por seu amor, sua paciência, seus bons exemplos e sua grande amizade! Sei que não estará aqui para ver a 
conclusão de meu doutorado, mas por um motivo muito digno e justo que é o de servir ao Senhor em uma missão de tempo integral.

Ao meu querido marido Gerson agradeço por sua amizade, amor e companheirismo verdadeiros e profundos desde que nos conhecemos. Agradeço por sempre me ouvir, ajudar e aconselhar em todas as áreas de minha vida. Obrigada por sempre me fazer sorrir quando estou desesperada ou triste. Sou muito feliz por você dividir sua vida comigo, por me ajudar a prosseguir lutando pelos meus objetivos e por me incentivar a prosseguir nessa área dentro da qual tenho dedicado meus estudos de pós-graduação.

À minha amiga e cunhada Geórgia agradeço por sempre me ouvir e me apoiar em diferentes fases de minha vida, incluindo o período de desenvolvimento de meus estudos de pós-graduação, sempre me dando alento e força para prosseguir com fé, diligência e alegria.

À minha orientadora, Prof. ${ }^{a}$ Dra. Claudia Regina Furquim de Andrade, agradeço imensamente por todas as oportunidades de aprendizado e crescimento profissional que tem me proporcionado ao longo desses anos de USP. Muito obrigada por confiar em mim e acreditar em meu trabalho! 
Obrigada pela grande oportunidade que me deu de poder estudar a educação mediada por tecnologia dentro da Fonoaudiologia, durante o mestrado e 0 doutorado, dentro da instituição em que me formei e na qual tenho o prazer de trabalhar. Obrigada pelas correções e contribuições para a constante melhoria de meu trabalho e também por respeitar as diferentes fases pelas quais tenho passado em minha vida pessoal e profissional desde que iniciei meus estudos em seu grupo. Sempre serei muito grata pela parceria e por toda sua orientação! Fico muito feliz por poder continuar trabalhando e desenvolvendo pesquisas em seu laboratório. É um prazer poder trabalhar sobre sua direção, dentro de um grupo que preza pela prática baseada em evidências e pela excelência em pesquisa e prática dentro da Fonoaudiologia.

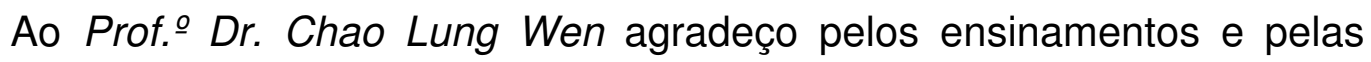
oportunidades que me proporcionou, desde de minha participação nas atividades da Liga de Telemedicina e Telessaúde da FMUSP até depois da graduação, dentro da Disciplina de Telemedicina. Por seu intermédio pude conhecer a Educação mediada por Tecnologia, área à qual tenho me dedicado com alegria. Admiro sua dedicação ao estudo e aplicação dos diferentes objetos educacionais interativos para a melhoria da educação em saúde nas comunidades e da formação dos profissionais de saúde. 
À Prof ${ }^{a}$ Dra. Débora Maria Befi Lopes agradeço inicialmente por ter me aceito prontamente em seu laboratório para que eu pudesse realizar a Iniciação Científica, passo de extrema importância para meu ingresso no universo da pesquisa. Agradeço também por todas as contribuições que trouxe para o aperfeiçoamento de meus estudos de pós-graduação por meio de sua participação em minhas bancas de qualificação e defesa no mestrado e da banca de qualificação para o doutorado.

À Prof. ${ }^{-}$Dra. Daniela Regina Molini-Avejonas agradeço pela parceria de trabalho desde 2011, sempre muito ética e agradável, e por ser uma incentivadora e colaboradora para meu desenvolvimento acadêmico e profissional nas áreas de Telessaúde e Teleducação em Fonoaudiologia. Agradeço também pela oportunidade de trabalhar com você, Prof. ${ }^{a}$ Dra. Alessandra Gianella Samelli e Dra. Cibelle Albuquerque de La Higuera Amato na elaboração da revisão sistemática intitulada "A systematic review of the use of telehealth in Speech-Language and Hearing Sciences", a qual foi aceita pelo Journal of Telemedicine and Telecare e está em fase de publicação. Foi um trabalho muito árduo, mas recompensador!

À Prof ${ }^{a}$ Dra. Mariangela Lopes Bitar agradeço pela parceria de trabalho desde 2011 dentro de seu laboratório na área de Promoção de Saúde nas 
Funções Orofaciais, tanto para a assistência da população como para a formação de novos fonoaudiólogos.

Às minhas colegas do LIF de Fluência, Funções da Face e Disfagia, agradeço pela companhia, amizade, apoio e por todos os conselhos e ensinamentos que me dão por meio do trabalho de excelência que desenvolvem. Dra. Fernanda Chiarion Sassi, Dra. Fabíola Staróbole Juste, Dra. Talita Maria Fortunato-Tavares e Ms. Ana Paula Ritto é sempre muito bom trabalhar com vocês!

À Dra. Fernanda Chiarion Sassi agradeço em especial pela parceria e pelo auxílio que me deu durante o mestrado e pelas grandes contribuições que deu para este trabalho de doutorado durante sua participação em minha banca de qualificação.

Agradeço à Dra. Danielle Pedroni Moraes pela amizade, exemplo de profissionalismo, ética e humanismo na atuação dentro da Fonoaudiologia e pelas grandes contribuições que forneceu para este trabalho durante sua participação em minha banca de qualificação. 
Agradeço também à Dra. Ana Manhani Cáceres-Assenço por sua amizade, por toda a ajuda que me deu durante os anos de minha graduação, sendo minha "madrinha" e me auxiliando em muitas coisas que precisei. Agradeço em especial por ter realizado as análises estatísticas deste trabalho, com tanto profissionalismo e qualidade.

À querida amiga e colega de trabalho no HCFMUSP Ms. Dicarla Motta Magnani agradeço por sua amizade preciosa, alegria, carinho, exemplo de dignidade e profissionalismo, pelos ensinamentos e por sempre me ouvir e aconselhar em diferentes aspectos de minha vida. Tem sido um grande prazer aprender com você, comemorar os sucessos e superar as dificuldades! Muito obrigada por tudo!

À Ms. Gisele Chagas de Medeiros agradeço também pela amizade e parceria durante nossos estudos no mestrado e principalmente no doutorado. Foram muitos desafios e anseios divididos! Obrigada pelo apoio em toda essa jornada e pelas risadas de descontração. 
À Ms. Lais Garcia Carpel Wenceslau agradeço pela amizade, companhia, ajuda e por me ouvir em muitas ocasiões, tanto no que se refere ao trabalho e estudo, como também à minha vida pessoal.

A todos os estudantes do curso de Fonoaudiologia da FMUSP que foram sujeitos desta pesquisa agradeço imensamente por terem aceitado participar de meu estudo, entrando em uma nova era no ensino superior em Fonoaudiologia, em que me proponho a estudar diferentes possibilidades de objetos educacionais interativos que possam ser aplicados e avaliados para contribuir com a formação em Fonoaudiologia. 
Esta tese está em conformidade com as seguintes normas, em vigor no momento desta publicação:

Referências: adaptado de International Committee of Medical Journals Editors (Vancouver).

Universidade de São Paulo. Faculdade de Medicina. Divisão de Biblioteca e Documentação. Guia de apresentação de dissertações, teses e monografias. Elaborado por Anneliese Carneiro da Cunha, Maria Julia de A. L. Freddi, Maria F. Crestana, Marinalva de Souza Aragão, Suely Campos Cardoso, Valéria Vilhena. 3a ed. São Paulo: Divisão de Biblioteca e Documentação; 2011.

Abreviaturas dos títulos dos periódicos de acordo com o List of Journals Indexed in Index Medicus. 
LISTA DE ABREVIATURAS E SIGLAS......................................................ii

LISTA DE FIGURAS ..............................................................................

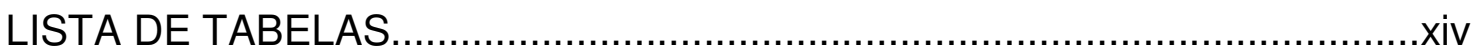

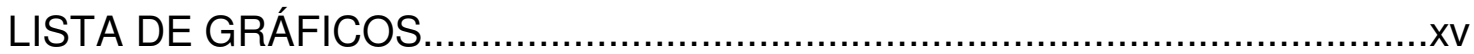

RESUMO

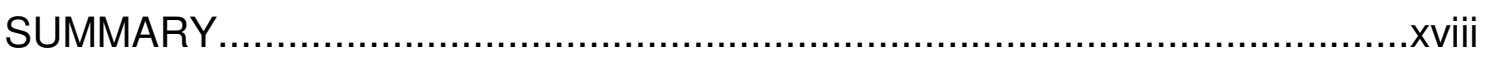

APRESENTAÇÃO

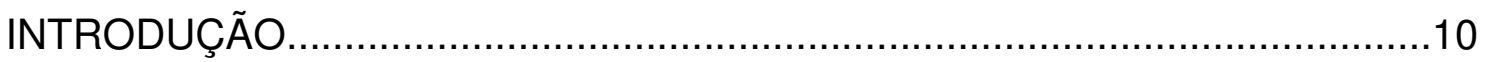

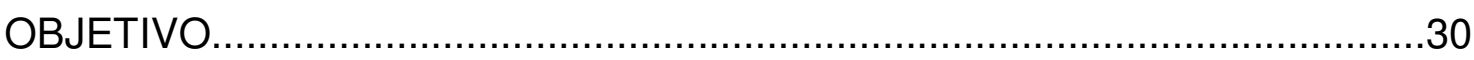

MÉTODO

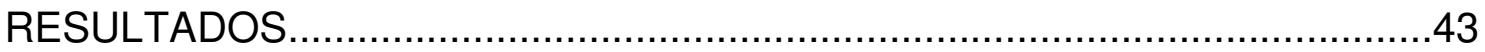

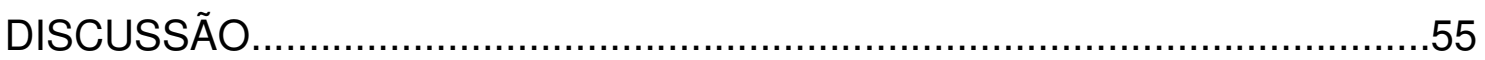

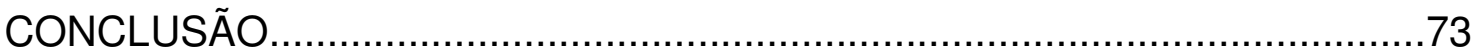

ANEXOS

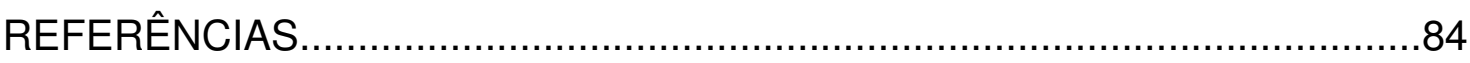


ARCS: Atenção, Relevância, Confiança e Satisfação/ Attention, Relevance, Confidence, and Satisfaction

MVP: Motivação, Vontade e Desempenho/ Motivation, Volition and Performance

IMMS: Instructional Materials Motivation Survey

M1: Método interativo 1

MI2: Método interativo 2

MT: Método tradicional

FMUSP: Faculdade de Medicina da Universidade de São Paulo

SMFO: Sistema Miofuncional Orofacial

Gl: Grupo 1

GII: Grupo 2

GIII: Grupo 3

AMIOFE-E: Avaliação Miofuncional Orofacial com Escores - Expandido 
LISTA DE FIGURAS

Figura 1 - Dados da distribuição dos participantes do estudo...........................43 
Tabela 1 - Distribuição de frequência do gênero por grupo 44

Tabela 2 - Estatística descritiva da idade dos sujeitos. .44

Tabela 3 - Estatística descritiva do desempenho na prova prática por grupo...45 Tabela 4 - Estatística descritiva da pontuação no questionário IMMS por grupo 48

Tabela 5 - Estatística descritiva dos resultados obtidos na avaliação de desempenho prático de acordo com o grau de motivação, considerando os diferentes grupos. .51

Tabela 6 - Distribuição de frequência do grau de motivação por grupo .53 Tabela 7 - Estatística descritiva dos resultados obtidos na avaliação de desempenho prático de acordo com o grau de motivação, independente do método de aprendizagem 54 
Gráfico 1 - Comparação entre a pontuação média dos grupos na avaliação de desempenho prático. 45

Gráfico 2 - Comparação entre os domínios do questionário de motivação em cada grupo 46

Gráfico 3 - Comparação entre a pontuação média total dos grupos no questionário de motivação. 49

Gráfico 4 - Comparação entre a pontuação média dos grupos nos diferentes aspectos do questionário IMMS. .50

Gráfico 5 - Comparação dos resultados obtidos na avaliação de desempenho prático de acordo com o grau de motivação em cada grupo. 52

Gráfico 6 - Comparação dos resultados obtidos na avaliação de desempenho prático de acordo com o grau de motivação, independente do método de aprendizagem. 
Melo SR. Educação mediada por tecnologia em fonoaudiologia: uma comparação entre três métodos de aprendizagem sobre o sistema miofuncional orofacial [Tese]. São Paulo: Faculdade de Medicina, Universidade de São Paulo; 2015.

O objetivo deste estudo foi comparar três métodos de aprendizagem sobre Anatomia e Fisiologia do Sistema Miofuncional Orofacial (SMFO) em relação ao desempenho prático e à motivação para a aprendizagem de estudantes de Fonoaudiologia. Participaram 36 estudantes do segundo ano de graduação, em disciplina obrigatória, após assinatura de termo de consentimento livre e esclarecido. Cada estudante foi alocado randomicamente em um dentre três grupos: Grupo I (Gl) - 12 participantes do Método Interativo 1 (MI1); Grupo II (GII) - 12 participantes do Método Interativo 2 (MI2); Grupo III (GIII) - 12 participantes do Método Tradicional (MT). Os métodos de aprendizagem foram aplicados durante horário de estudo complementar semanal (uma hora de duração), após aula expositiva da disciplina, contendo os mesmos tópicos de estudo relacionados à aula. Concluída a aplicação dos três métodos de aprendizagem, foi aplicada avaliação de desempenho prático sendo requerido dos estudantes que realizassem procedimentos referentes à avaliação fonoaudiológica segundo critérios do protocolo de Avaliação Miofuncional Orofacial com Escores - Expandido. Em outro dia, foi aplicado o questionário Instructional Materials Motivation Survey (IMMS) para avaliação da motivação para a aprendizagem. O questionário avalia quatro aspectos da motivação: atenção, relevância, confiança e satisfação (modelo ARCS) segundo a percepção do estudante. Os dados coletados foram submetidos à análise estatística no software SPSS versão 21 . A comparação da pontuação entre os grupos tanto para a avaliação de desempenho prático como para a avaliação da motivação foi realizada pela ANOVA seguida pelo teste post hoc de Tukey. O nível de significância adotado foi de $5 \%$. Os resultados indicaram que os grupos se comportaram de forma semelhante na avaliação de desempenho prático. Em relação à comparação quanto à motivação os grupos diferiram em todos os aspectos avaliados e na pontuação total $\left(F_{2,33}=3691,17 p<0,001\right)$. $O$ Gll teve a maior pontuação geral (GI x Gll = p=0,015; GI x GIII = p=0,115; GII x GIII $=p<0,001)$. Com relação à atenção (GII $x$ GIII $=p=0,001)$ e à confiança (GII x GIII = p=0,003), o Gll teve maior pontuação que o GIII. Com relação à relevância, não houve diferença entre os grupos. Com relação à satisfação o Gll teve a maior pontuação (Gl x Gll = p=0,023; Gll x GIII = p<0,001). Na comparação entre o grau de motivação e os resultados da avaliação de desempenho prático embora o Gll tenha apresentado a maioria dos sujeitos com alto grau de motivação, não apresentou melhores resultados nesta avaliação quando comparado aos demais grupos. Neste estudo os resultados mostraram que o desempenho prático dos estudantes foi semelhante, independente do método de aprendizagem e do grau de motivação para a aprendizagem que tenham atingido. Foi observado que relevância dos métodos de aprendizagem propostos foi considerada semelhante, contudo o modelo 
computacional 3D foi mais eficiente para motivar os estudantes a aprenderem, tanto no que se refere ao processamento da motivação (atenção e confiança) quanto ao processamento de resultados (satisfação). Esses resultados corroboram resultados de estudos recentes nas ciências da saúde, e trazem novas perspectivas dentro da educação mediada por tecnologia em Fonoaudiologia.

Descritores: fonoaudiologia; anatomia; fisiologia; aprendizagem; instrução por computador; motivação. 
Melo SR. Technology-mediated learning in speech-language and hearing sciences: a comparison between three learning methods about the orofacial miofuncional system [Thesis]. São Paulo: "Faculdade de Medicina, Universidade de São Paulo"; 2015.

The objective of this study was to compare three learning methods as means of teaching Anatomy and Physiology of the Orofacial Myofunctional System (OMFS) in relation to clinical performance and learning motivation to secondyear Speech-Language and Hearing Sciences undergraduate students. The study was conducted with 36 students which were participants after signing a free and informed consent. Each student was randomly allocated to one of three groups: Group I (GI) - 12 participants in the Interactive Method 1 (Ml1); Group II (GII) - 12 participants in the Interactive Method 2 (MI2); Group III (GIII) - 12 participants in the Traditional Method (MT). Learning methods were applied during weekly complementary study schedule (one hour), after the discipline lectures. After the conclusion of the three learning methods application, a clinical performance assessment was applied and it was required from the students to apply a clinical assessment following the criteria stablished in the Expanded protocol of Orofacial Myofunctional Evaluation with scores. On another day, the Instructional Materials Motivation Survey questionnaire (IMMS) was applied for evaluating the students' learning motivation. The questionnaire assesses four aspects of motivation: attention, relevance, confidence and satisfaction (ARCS model) as judged by the student. Data were statistically analyzed using SPSS software version 21. The comparison of scores between the groups for both the clinical performance assessment and learning motivation assessment was performed by ANOVA followed by Tukey post hoc test. The significance level adopted was of $5 \%$. The results indicated that no differences were identified between the three groups in relation to the clinical performance assessment. Regarding the between groups comparison for learning motivation, the groups differed in all evaluated aspects and total score $(F 2,33=3691.17 p<0.001)$. The Gll had the highest overall score $(G I \times G l l=p$ $=0.015 ; \mathrm{Gl} \times \mathrm{Glll}=\mathrm{p}=0.115$; GII GIII $\mathrm{x}=\mathrm{p}<0.001$ ). Regarding attention (Gll GIII $x=p=0.001$ ) and confidence (GII GIII $x=p=0.003$ ), the Gll had higher scores than the GIII. With respect to relevance, there was no difference between groups. Regarding satisfaction Gll had the highest score (GI $\times$ GII = p $=0.023 ;$ Gll GllI $x=p<0.001$ ). Comparing the degree of motivation and clinical performance assessment results, although the Gll has presented most of the subjects with a high degree of learning motivation, it did not show better results in this assessment when compared to other groups. In this study, the results showed that the students' clinical performance was similar, regardless of the learning method and of the degree of learning motivation. It was observed that the proposed relevant learning methods were considered similar in terms of the relevance. The 3D computer model was more efficient to enhance students 
learning motivation, both as regards the motivational processing (related to attention and confidence) as the outcome processing (related to satisfaction). These results corroborate the results of recent studies in health sciences, and bring new perspectives in computer-assisted learning in Speech-Language and Hearing Sciences.

Descriptors: speech, language and hearing sciences; anatomy; physiology; stomatognathic system; learning; motivation; computer-assisted instruction. 
A tecnologia digital está atualmente inserida no cotidiano do estudante, por meio do uso de celulares, computadores, vídeo games e simuladores, para as mais diversas finalidades. Nesse sentido, tem aumentado o número de iniciativas e estudos que abordam o uso de diferentes objetos educacionais mediados por tecnologia, nos diferentes níveis da educação. A aplicação e a avaliação da efetividade de objetos educacionais mediados por tecnologia no ensino superior tem crescido nas Ciências da Saúde, e é uma temática com a qual estou envolvida desde o início de meu percurso acadêmico.

No ano de 2006, quando estava no segundo ano do curso de graduação em Fonoaudiologia da Faculdade de Medicina da Universidade de São Paulo, ingressei como membro da Liga de Telemedicina da mesma instituição (atualmente Liga de Telemedicina e Telessaúde - LTms), local em que iniciei os estudos sobre Educação mediada por Tecnologia nas ciências da Saúde.

No ano de 2007 fui eleita presidente da LTms e passei a representá-la em diferentes projetos de educação em saúde utilizando recursos para a Teleducação interativa, sobretudo dentro do "Projeto Jovem Doutor" (PJD) de educação em saúde para estudantes de Ensino Fundamental e Médio e suas comunidades. A partir de então, passamos a disseminar o PJD no estado de São Paulo e em outras cidades do país, em parceria entre a Disciplina de 
APRESENTAÇÃO

Telemedicina da FMUSP com outras universidades federais e estaduais: UFAM e UEA (Manaus e Parintins); UFMG (Belo Horizonte); UNCISAL (Maceió e Anadia); UFBA (Salvador). Dentro dessas parcerias, realizei trabalhos de capacitação (presencialmente e à distância) de estudantes de Ensino Fundamental, Médio e de Ensino Superior para a implantação e disseminação do projeto em suas localidades de origem.

Em 2008, concluí a graduação em Fonoaudiologia pela FMUSP, apresentando como trabalho de conclusão de curso a pesquisa que realizei como bolsista de Iniciação Científica da Fundação de Amparo à Pesquisa de São Paulo (sob o processo de no 06/61458-0), no Laboratório de Investigação Fonoaudiológica em Desenvolvimento de Linguagem e suas Alterações, sob orientação da Prof. ${ }^{a}$ Dra. Debora Maria Befi Lopes. O título do trabalho foi "Descrição das características iniciais da comunicação verbal em crianças com Alteração Específica de Linguagem em situação de fala espontânea". A partir desse trabalho foram publicados dois artigos científicos em revistas científicas da área de Fonoaudiologia:

1. Befi-Lopes DM, Rondon S. Características iniciais da comunicação verbal de pré-escolares com Alterações Específicas do Desenvolvimento da Linguagem em fala espontânea. Rev. soc. bras. fonoaudiol. 2010;15(3):415-420. ISSN 1516-8034 
APRESENTAÇÃO

2. Befi-Lopes DM, Rondon S. Redução de sílaba em fala espontânea nas alterações específicas de linguagem. Pró-Fono $R$. Atual. Cient. 2010;22(3):333-338. ISSN 0104-5687

No ano de 2009, ingressei como bolsista no projeto "Telemática e Telemedicina em Apoio à Atenção Primária à Saúde no Brasil", coordenado pelo Prof..$^{\circ}$ Chao Lung Wen, dentro da Disciplina de Telemedicina da FMUSP. Neste projeto, participei do desenvolvimento das atividades na área de Fonoaudiologia, específicas ou em equipe multiprofissional, dentro do Núcleo São Paulo do Programa Telessaúde Brasil (NSP - PTB): segunda opinião formativa para Fonoaudiólogos; orientações e elaboração de cursos interativos para capacitação de Agentes Comunitários de Saúde e de profissionais de saúde (Curso de capacitação em Saúde Vocal para Agentes Comunitários de Saúde; Grupo de Teleamamentação; e Curso de Especialização em Saúde Materno-Infantil - parceria com a UFMA); desenvolvimento científico de materiais educacionais interativos (áudios educacionais e computação gráfica 3D dentro do Projeto Homem Virtual - neste caso, desenvolvendo o Bebê Virtual - em parceria com profissionais de Digital Design, Fonoaudiologia, Medicina e Anatomia). Além disso, participei do processo de criação e desenvolvimento de um espaço digital interativo dentro da área do Núcleo de Apoio à Saúde da Família (NASF) do website do NSP - PTB, para a disponibilização de todos os materiais e cursos interativos desenvolvidos no 
APRESENTAÇÃO

projeto, além dos resumos dos trabalhos científicos elaborados por pesquisadores brasileiros na área de Fonoaudiologia e Telessaúde e publicados nacional e internacionalmente.

Neste mesmo ano, fui coautora do trabalho "Educação e promoção em saúde por meio do uso de tecnologia e ação de estudantes em suas comunidades", vencedor da categoria "Saúde e Prevenção" do IV Prêmio SAÚDE! da Editora Abril.

Em seguida, foi publicado em periódico internacional ISI o resumo de um trabalho do qual fui coautora, apresentado na "The Royal Society of Medicine Conference - Telemed \& eHealth '08: Optimising Patient Centred Care-the role of e-Health", em Londres, UK:

Macea DD, Rondon S, Chaar LJ, Wen CL. Public health education for young students aided by technology. J Telemed Telecare, 2009;15:159.

Os dois trabalhos acima citados foram originados a partir das atividades realizadas no "Projeto Jovem Doutor". 
APRESENTAÇÃO

No mesmo ano de 2009, foi desenvolvido na Disciplina de Telemedicina um jogo computacional sobre cirrose, por estudantes do curso de graduação em Medicina da FMUSP. A partir deste trabalho passei a me interessar pela área e comecei a pesquisar sobre o assunto. Em seguida, a partir de uma discussão com a Prof. ${ }^{a}$ Dra. Claudia Regina Furquim de Andrade, vimos que seria muito interessante realizar um estudo sobre 0 uso de jogos computacionais na área de Fonoaudiologia como proposta de estudo de mestrado.

Em 2010, com o projeto sobre o uso de jogos computacionais na área de Fonoaudiologia elaborado e aprovado, ingressei no Mestrado dentro do Programa de Ciências da Reabilitação, na área de Comunicação Humana, sob orientação da Prof. ${ }^{a}$ Dra. Claudia Regina Furquim de Andrade. Inicialmente, tivemos a ideia de elaborar e aplicar um jogo computacional específico sobre a Anatomia e Fisiologia do Sistema Miofuncional Orofacial para estudantes de Fonoaudiologia, no entanto verificamos que, para a proposta do Mestrado, seria mais viável aplicar primeiramente um jogo computacional já validado para a área e disponível no mercado e, a partir dos resultados, estudar a proposta do desenvolvimento do jogo próprio em etapa subsequente. 
APRESENTAÇÃO

No mesmo ano, fui coautora do trabalho "Educação e cultura em saúde espaço digital de ciência para promoção de saúde" que recebeu a "Menção Honrosa Colgate-Palmolive" no V Prêmio SAÚDE! da Editora Abril. Além disso, fui aprovada no concurso para Fonoaudiólogo do Departamento de Fisioterapia, Fonoaudiologia e Terapia Ocupacional da FMUSP, assumindo o cargo oficialmente a partir de 06/06/2011.

No ano de 2012 apresentei a dissertação intitulada "Uso de jogo interativo na aprendizagem de estudantes de Fonoaudiologia sobre o Sistema Miofuncional Orofacial" à Faculdade de Medicina da Universidade de São Paulo para obtenção do título de "Mestre em Ciências". Nesse trabalho estudei o efeito do uso de um jogo computacional na aprendizagem de estudantes de Fonoaudiologia sobre o Sistema Miofuncional Orofacial, comparado aos resultados do uso de um método tradicional de aprendizagem na mesma população. O estudo foi precursor na área de Fonoaudiologia, tendo sido publicado como artigo científico em periódico internacional no ano de 2013, no periódico BMC Medical Education, com o título "Computer game-based and traditional learning method: a comparison regarding students' knowledge retention", o qual está classificado como "Highly accessed" pelo periódico. 
Em 2014 foi publicado artigo intitulado "Referred speech-language and hearing complaints in the Western region of São Paulo, Brazil' no periódico Clinics, do qual fui coautora juntamente com a Prof. ${ }^{a}$ Dra. Daniela Regina Molini-Avejonas, Prof. ${ }^{a}$ Dra. Alessandra Gianella Samelli, Prof. ${ }^{a}$ Dra. Fátima Correa Oliver e Prof. ${ }^{a}$ Dra. Simone Rennó Junqueira. Esse trabalho foi resultado de parceria iniciada em 2011, quando comecei a trabalhar no Laboratório de Investigação Fonoaudiológica em Atenção Primária em Linguagem (atual Laboratório de Investigação Fonoaudiológica em Atenção à Saúde), sob coordenação da Prof. ${ }^{a}$ Dra. Daniela Regina Molini-Avejonas.

No ano de 2015 concluí a elaboração de uma revisão sistemática intitulada "A systematic review of the use of telehealth in Speech-Language and Hearing Sciences", a qual foi escrita em coautoria com a Prof. ${ }^{a}$ Dra. Daniela Regina Molini-Avejonas, Prof. ${ }^{a}$ Dra. Alessandra Gianella Samelli e Dra. Cibelle Albuquerque de La Higuera Amato. $\mathrm{O}$ artigo foi aceito pelo Journal of Telemedicine and Telecare e está em fase de publicação.

Como proposta para a continuidade do estudo realizado durante 0 mestrado foi indicada a realização de uma nova pesquisa na qual fossem contempladas, além da avaliação objetiva de conhecimento, a avaliação da motivação dos estudantes para a aprendizagem a partir do uso de jogos 
APRESENTAÇÃO

computacionais. Além disso, foi concluído que seria importante investigar a relação entre o uso desses jogos e o desempenho dos estudantes em atividades relacionadas à prática clínica no que se refere aos conhecimentos sobre Anatomia e Fisiologia do Sistema Miofuncional Orofacial.

Além dos resultados apresentados na literatura sobre o uso de jogos computacionais para o ensino e a aprendizagem, tem crescido o número de estudos que evidenciam resultados positivos a partir do uso de modelos computadorizados, simulações e animações em contextos de ensino e aprendizagem. Considera-se que esse tipo de objeto educacional pode tornar visíveis conceitos abstratos e facilitar o processo de aprendizagem. Na área de Fonoadiologia existem poucos estudos sobre essa temática disponíveis na literatura, os quais abordam os efeitos do uso desse tipo de recurso para a aprendizagem em curto prazo, por meio de avaliações de conhecimento teórico.

Assim, a proposta desta tese foi delineada a partir de questionamentos acerca da efetividade do uso de objetos educacionais mediados por tecnologia no ensino superior, os quais foram também norteadores de minha dissertação de mestrado. No presente estudo foi proposta, além da comparação entre o uso de um jogo computacional e o uso de método tradicional de aprendizagem, 
APRESENTAÇÃO

a comparação destes com um método interativo que contempla o uso de um modelo computacional com animações em 3D. Essas comparações foram feitas no que se refere ao desempenho prático dos estudantes e a aspectos relacionados à motivação para a aprendizagem. 
INTRODUÇÃO

O conhecimento acerca dos conceitos relacionados à Anatomia e à Fisiologia é de extrema importância tanto para estudantes como para profissionais da área de Fonoaudiologia no que se refere à orientação dos processos de avaliação, diagnóstico e intervenção fonoaudiológica ${ }^{1-3}$.

Com o avanço das tecnologias de informação, ambientes educacionais com apoio de computadores têm sido utilizados para integrar laboratórios de Anatomia e Fisiologia a fim de potencializar a aprendizagem sobre estes conteúdos $^{4-6}$. Resultados positivos têm sido obtidos, no que se refere à ampliação do conhecimento acerca dos temas abordados e ao interesse dos estudantes por ferramentas tecnológicas de ensino-aprendizagem ${ }^{7-9}$.

Pesquisadores da área de educação mediada por tecnologia afirmam que as tecnologias computadorizadas podem transformar a aprendizagem por meio do acesso à informação, oferecendo a professores e estudantes a oportunidade de colaborar com pares e especialistas, expressar e comunicar ideias e explorar tópicos que, de outras maneiras, seriam mais difíceis para se apresentar e discutir em sala de aula ${ }^{10}$.

Estudos mostram que objetos e ambientes educacionais que ofereçam alternativas para o desenvolvimento do raciocínio norteado para a resolução de 
INTRODUÇÃO

problemas, considerando os conhecimentos prévios do estudante e sua arquitetura cognitiva, são mais apropriados, pois podem reduzir a demanda cognitiva para a memória operacional na formalização dos novos conhecimentos e facilitar a aprendizagem ${ }^{11-15}$. Um exemplo desse tipo de objeto de aprendizagem são os jogos computacionais que tem sido desenvolvidos para aplicação em diferentes níveis educacionais ${ }^{16,17}$. Esses jogos contem características relacionadas à contextualização e à resolução de problemas, oferecendo ao estudante diferentes possibilidades de estratégias para alcançar os objetivos preestabelecidos ${ }^{18}$.

Para que um jogo computacional possa contribuir para a aprendizagem é necessário que se estabeleça um ambiente com o qual o estudante se identifique e em que receba o feedback acerca de suas ações e novas questões e/ou problemas a serem solucionados ${ }^{19,20}$. Além disso, o jogo deve conter questões cuja complexidade favoreça o desempenho do estudante e seu processo de aprendizagem ${ }^{21,22}$. $\mathrm{O}$ jogo deve apresentar objetivos e regras bem estabelecidos e ser divertido para que o estudante deseje jogar e atribuir valor a este tipo de objeto educacional, integrando os objetivos do ensino com seus próprios interesses e objetivos ${ }^{20,23}$. 
INTRODUÇÃO

Habilidades cognitivas como a memória, a atenção, o pensamento crítico, além da elaboração e confirmação de hipóteses, podem ser desenvolvidas por meio do uso de jogos computacionais durante o processo de aprendizagem ${ }^{23-26}$. Além disso, os estudantes podem passar a realizar ações fundamentadas e a construir seu conhecimento de maneira mais integrativa (conhecer e agir), apresentando maior motivação para aprender ${ }^{18,20,27,28}$.

Atualmente ainda não existe um consenso sobre os efeitos dos jogos computacionais sobre o desempenho dos estudantes em geral ${ }^{29}$, contudo resultados positivos têm sido encontrados desde que jogos de diferentes modalidades passaram a ser incorporados no ensino superior, incluindo cursos da área de saúde ${ }^{30}$. Estudo pioneiro mostrou que estudantes de Medicina que utilizaram um jogo computacional sobre administração de um determinado medicamento obtiveram maior porcentagem de acerto em decisões relacionadas ao tema ${ }^{31}$.

No que se refere ao desempenho prático de estudantes e profissionais a partir do uso de jogos computacionais em diferentes estudos na área de ensino em cirurgia concluíram que 0 uso desses objetos educacionais melhora 0 desempenho prático referente ao uso de técnicas cirúrgicas ${ }^{32,33}$. Em outros estudos os resultados do uso de jogos computacionais no desempenho prático 
INTRODUÇÃO

de seus usuários foram equivalentes a métodos tradicionais de aprendizagem $^{34,35}$.

Na Fonoaudiologia, estudo precursor na área mostrou que o uso de um jogo computacional como ferramenta complementar ao processo de ensino e aprendizagem beneficiou os estudantes tanto quanto o método tradicional de aprendizagem, no que se refere à retenção de conhecimento teórico em curto prazo, sendo o método tradicional mais eficiente para a retenção de conhecimento em longo prazo $^{36}$. Não existem estudos nessa área que tenham avaliado o desempenho prático de estudantes a partir do uso de jogos computacionais.

O desempenho relacionado às habilidades de prática clínica de estudantes de graduação que utilizam jogos computacionais para a aprendizagem tem sido avaliado principalmente por meio de provas teóricas $^{31,37}$ e situações de aplicação de exames clínicos objetivos estruturados ${ }^{30,38}$ (Objective Structured Clinical Examinations).

Embora existam evidências de que o uso de jogos, incluindo jogos computacionais, traz benefícios à formação de estudantes da área da saúde, é grande a necessidade de realização de novos estudos que conduzam 
INTRODUÇÃO

avaliações antes e após o uso destes jogos, a fim de analisar cuidadosamente os resultados no que se refere à aprendizagem, considerando aspectos educacionais e clínicos, além da retenção dos conhecimentos adquiridos ou reforçados por meio deste tipo de objeto educacional ${ }^{30}$.

Além dos resultados apresentados na literatura sobre o uso de jogos computacionais para o ensino e a aprendizagem, estudos tem mostrado que a integração de simuladores computacionais em contextos de ensino e aprendizagem pode proporcionar ao estudante oportunidades para promover sua compreensão sobre fenômenos não observáveis na ciência ${ }^{39,40}$ e de tornar visíveis conceitos abstratos ${ }^{41,42}$. O uso de recursos visuais pode aumentar o conhecimento conceitual e a habilidade espacial dos estudantes, bem como facilitar o processamento de dados complexos, tornar o processo científico mais dinâmico e prover maneiras para o estudo de fenômenos interessantes e complexos $^{40,42}$.

Simuladores computacionais apresentam modelos teóricos ou simplificados de componentes, fenômenos ou processos do mundo real e tem o potencial de tornar a aprendizagem mais interativa e autêntica, conceitos abstratos mais concretos ${ }^{43}$ e processos tácitos visíveis ${ }^{10}$. Exemplos desse tipo de ferramenta incluem animações, visualizações e laboratórios interativos ${ }^{10}$. No 
INTRODUÇÃO

presente estudo será dada ênfase à utilização de animações e modelos computacionais 3D para o ensino e a aprendizagem.

O conceito de animação envolve 0 ato, processo ou resultado de transmitir vida e pode ser definido também como uma série de mudanças rápidas na tela do computador sugerindo movimento ao usuário ${ }^{44}$. Considerando-se o contexto da aprendizagem, as animações tem o objetivo de dar ao estudante uma apresentação o mais exata possível de um processo ou procedimento, a fim de facilitar a geração de um modelo mental adequado ${ }^{45}$. Animações são efetivas especialmente na visualização de processos que não podem ser vistos ou que são difíceis de explicar em sala de aula ${ }^{40,45}$.

Animações podem viabilizar a criação de representações mentais sobre conceitos, fenômenos e processos, bem como substituir processos cognitivos desafiadores, como imaginação e abstração ${ }^{40}$. Efeitos positivos do uso de animações educacionais têm sido encontrados no que se refere ao desenvolvimento das habilidades de pensamento e reflexão, à compreensão de conceitos estudados e à motivação dos estudantes para a aprendizagem ${ }^{40-42}$.

Conforme indicam os resultados de revisão sistemática publicada recentemente ${ }^{10}$, na maior parte dos estudos apresentados na literatura o uso 
INTRODUÇÃO

dos diferentes tipos de simuladores computacionais, incluindo animações, tem sido mais efetivo do que o uso de métodos tradicionais de ensino e aprendizagem (aulas expositivas, atividades com uso de textos ou atividades práticas físicas) ou tão efetivo quando o uso destes métodos. Nesse mesmo estudo, é discutido que simulações computadorizadas são efetivas para a aprendizagem quando: são aplicadas como complemento de outras ferramentas ou métodos tradicionais de ensino e aprendizagem; contém estruturas de suporte de alta qualidade e encorajam a reflexão do estudante.

Algumas recomendações sobre o uso de animações para o ensino e a aprendizagem citadas na literatura, indicam que as animações devem: ser utilizadas quando estruturas espaciais complicadas e processos dinâmicos estão envolvidos; ser integradas com explicações verbais; estar relacionadas com o currículo estabelecido para o ensino de determinada disciplina ou área; ter uma significativa contribuição para o processo de aprendizagem e encorajar a colaboração entre estudantes ${ }^{42,45,46}$.

Animações têm sido utilizadas no Ensino superior em Ciências da Saúde para aumentar a compreensão dos graduandos sobre processos, anatomia e técnicas cirúrgicas ${ }^{47}$. Em estudo da área de Medicina os resultados de testes formais (aplicados antes, durante e após a intervenção) mostraram que, no que 
INTRODUÇÃO

se refere à compreensão de lições sobre o processo de replicação do ácido desoxirribonucleico (DNA), o desempenho de estudantes que utilizaram animações em 3D para a aprendizagem do tema foi superior ao daqueles que utilizaram livros-texto ${ }^{48}$. Estudantes de Medicina Veterinária que utilizaram animações em 3D para a aprendizagem sobre anatomia funcional foram capazes de detalhar de modo mais completo os efeitos da ruptura do ligamento cranial cruzado no menisco medial em cachorros do que aqueles que utilizaram materiais contendo ilustrações não animadas sobre o mesmo tema ${ }^{47}$.

$\mathrm{Na}$ Fonoaudiologia, estudo realizado para avaliar a eficácia de um software contendo animações em computação gráfica 3D integrado a informações em áudio e vídeo para a aprendizagem de anatomia e fisiologia da fonação mostrou que houve um aumento significativo no conhecimento teórico dos estudantes sobre os temas abordados após sua utilização ${ }^{49}$. Em outro estudo da área, a utilização de um modelo computacional 3D como complemento de um método tradicional de ensino sobre a anatomia do osso temporal se mostrou mais eficiente para a aprendizagem do que a utilização exclusiva do método tradicional, segundo demonstrado pelo desempenho dos estudantes de ambos os grupos em um exame final de disciplina de anatomia ${ }^{50}$. 
INTRODUÇÃO

Além da importância do uso de simuladores computacionais para a melhora na aprendizagem conceitual, é importante estudar seu impacto no que se refere ao desempenho prático dos estudantes, sobretudo nas áreas das Ciências da Saúde. As habilidades referentes à prática clínica de estudantes de graduação que utilizam simuladores computadorizados para a aprendizagem tem sido avaliado principalmente por meio de provas teóricas ${ }^{41,51,52}$, situações de aplicação de exames clínicos objetivos estruturados ${ }^{53}$ (Objective Structured Clinical Examinations), com uso de pacientes padronizados ${ }^{51}$, além de avaliações dentro de ambientes virtuais ${ }^{54}$.

No que se refere ao desempenho prático dos estudantes relacionado à administração de ventilação mecânica na área de Medicina Veterinária, resultados de um estudo recente mostraram que o desempenho geral dos sujeitos que estudaram por meio utilizando um simulador computacional foi equivalente ao daqueles que estudaram por meio de aula tradicional e textos. Entretanto, os estudantes com maiores escores em avaliação de conhecimentos prévios obtiveram melhor desempenho quando utilizaram o simulador $^{52}$. Os estudantes referiram que o uso do simulador durante suas atividades de prática clínica na formação acadêmica seria muito útil como uma ferramenta de revisão de conceitos e investigação relacionada a desafios sobre o tema. 
INTRODUÇÃO

Tópicos relacionados à anatomia do osso temporal humano também foram mais bem compreendidos por estudantes de Medicina que utilizaram um simulador com realidade virtual ${ }^{54}$. No mesmo estudo, residentes informaram que o uso do simulador foi melhor para a compreensão dos tópicos relacionados à anatomia, contudo ainda se sentiam mais confortáveis utilizando os métodos tradicionais de dissecção de cadáveres para as atividades mais relacionadas à prática e futuros procedimentos cirúrgicos.

Estudos na área de Fonoaudiologia que apresentam resultados do uso de simuladores de pacientes são relativamente recentes e tem sido objeto de estudo de algumas pesquisas ${ }^{55}$. Essas simulações são realizadas por meio de atores ou estudantes que atuam como pacientes padronizados reproduzindo comportamentos e situações baseadas na realidade da clínica de Fonoaudiologia ${ }^{56,57,58}$, em sua grande maioria. As simulações também são realizadas por meio do uso de pacientes virtuais ${ }^{59}$ ou da exploração de manequins de alta tecnologia ${ }^{60}$. Os objetivos desses estudos estão relacionados ao fornecimento de maior suporte aos estudantes ou profissionais da área para atuação com pacientes em diferentes especialidades e contextos, sem comprometer a segurança de pacientes reais. Os resultados dos poucos estudos sobre o tema são positivos, contudo ainda há necessidade de mais estudos para a confirmação de que a aprendizagem por meio do uso de simuladores é comparável à aprendizagem tradicional ${ }^{55,61}$. 
INTRODUÇÃO

A avaliação do desempenho prático nos referidos estudos com uso de simuladores de pacientes na Fonoaudiologia tem sido realizada principalmente a partir da aplicação de questionários de percepção do estudante ou profissional sobre sua aprendizagem durante a interação com os simuladores de pacientes ${ }^{60,62}$. Outras formas de avaliação contemplam a observação das habilidades e técnicas demonstradas pelo estudante ou profissional perante situações em que precisa solucionar problemas, a partir de sua interação com o simulador, dentro de um contexto clínico ou hospitalar ${ }^{57,60}$. O fortalecimento e validação desse tipo de avaliação do desempenho dos alunos em tais ambientes de simulação para a aprendizagem poderá trazer mais informações sobre como efetivamente este tipo de estratégia apoia o desenvolvimento da capacidade dos alunos para aplicar o conhecimento à prática clínica ${ }^{62}$.

Embora sejam encontrados na literatura alguns estudos sobre o uso de simuladores de pacientes na Fonoaudiologia, não são apresentados atualmente estudos que discorram sobre avaliações de resultados do uso de simuladores computacionais com animações 3D, para aprendizagem sobre Anatomia e Fisiologia e seu impacto no desempenho prático de estudantes de Fonoaudiologia, conforme proposto no presente estudo. Os poucos estudos que utilizaram esse tipo de objeto educacional, citados anteriormente, apresentaram resultados referentes à aprendizagem de conceitos medida por meio de avaliações de conhecimento teórico. 
INTRODUÇÃO

Além da importância do uso de objetos computacionais interativos para a aquisição de conhecimento e mudança no desempenho prático do estudante, estudos têm evidenciado resultados positivos e muito relevantes sobre seu uso no que se refere à motivação para a aprendizagem ${ }^{50,63,64}$. A motivação é 0 desejo de mudança do indivíduo proveniente da situação com a qual interage ${ }^{65}$; provê uma fonte de energia que é responsável pelo esforço que os estudantes decidem imprimir para aprender, o tempo que estarão dispostos para sustentar uma atividade e como eles se sentem ligados à atividade ${ }^{66}$. Desse modo, entende-se que a motivação é um componente muito importante a ser considerado e avaliado durante os processos de ensino e aprendizagem.

O aumento da motivação para a aprendizagem tem sido revelado como um dos maiores benefícios do uso de jogos computacionais na educação mencionados na literatura ${ }^{37,63,67}$. Propostas de aprendizagem que incluem o uso desses jogos têm promovido maior motivação ao estudante e melhores resultados em termos educacionais quando comparadas a propostas mais tradicionais ${ }^{68,69}$. Por meio da participação ativa nas decisões solicitadas pelos jogos o estudante pode aumentar seu nível de atenção e seu engajamento durante o processo de aprendizagem, o que o leva a atingir maiores níveis de motivação, resultando em efeitos favoráveis à aprendizagem ${ }^{69,70}$. 
INTRODUÇÃO

No que se refere a modelos computacionais $3 \mathrm{D}$ e ambientes virtuais alguns estudos revelam que as suas capacidades imersivas e interativas despertam e incentivam a motivação e o engajamento dos estudantes ${ }^{71-74}$. Pesquisas sugerem que as tecnologias de simulação quando integradas ao currículo educacional têm o potencial de melhorar o desempenho do estudante, sobretudo para aqueles cujas aulas tradicionais, a coleta passiva de informações e o pensamento linear podem não promover engajamento total durante os processos de aprendizagem ${ }^{52,75}$. Estudos da área de saúde mostram que por meio do uso ativo de simuladores computacionais os estudantes se tornam mais engajados, podem ver de forma mais concreta os resultados de suas decisões relacionadas a conceitos básicos e procedimentos clínicos que realizam e apresentam melhora no desempenho relacionado a habilidades clínicas ${ }^{51,52}$.

Um dos principais modelos que tem norteado a avaliação de métodos e ambientes de aprendizagem, no que se refere ao estímulo motivacional para o desempenho do estudante ${ }^{64,72,76,77}$, é o modelo de Atenção, Relevância, Confiança e Satisfação (Attention, Relevance, Confidence, and Satisfaction ARCS) de design motivacional ${ }^{78,79}$. Esse modelo se baseia na teoria de que as pessoas agem de acordo com suas expectativas e avaliações, considerando que o comportamento humano é uma função composta pela probabilidade percebida para o sucesso (esperança) e o impacto percebido do sucesso (valor). No contexto da aprendizagem, todas as estratégias motivacionais baseadas no modelo ARCS, portanto, são desenvolvidas para melhorar as 
INTRODUÇÃO

expectativas e valores que orientam os comportamentos dos estudantes para aprender ${ }^{77}$.

Teoricamente o modelo ARCS mede a quantidade de esforço investido pelos alunos para realizar a tarefa de aprendizagem ${ }^{80,81}$. Além disso, pode ilustrar como os estudantes se comportam diante de propostas de aprendizagem baseada em computadores quando motivados (ou desmotivados) considerando também fatores motivacionais extrínsecos (oriundos de sua interação com o ambiente de aprendizagem e o objeto educacional aplicado).

O modelo ARCS de design motivacional sugere que a motivação para a aprendizagem depende de quarto componentes perceptuais: atenção, relevância, confiança e satisfação ${ }^{82}$. A atenção se refere à resposta do estudante para o estímulo percebido a partir do processo instrucional; a relevância auxilia o estudante a associar seus conhecimentos e experiências prévias com a nova instrução fornecida; a confiança salienta a importância da construção de expectativa positiva do estudante para o seu desempenho na tarefa de aprendizagem; a satisfação aparece próxima ao fim do processo de aprendizagem, quando o estudante tem a oportunidade de praticar o conhecimento ou habilidades recém-adquiridas. Uma vez que o 
INTRODUÇÃO

modelo considera o desenvolvimento da motivação como um processo dinâmico e interativo, a flutuação de um componente motivacional inevitavelmente impacta todos os outros componentes ${ }^{77}$. Assim, cada um dos componentes do modelo ARCS desempenha um papel crítico para a motivação dos estudantes durante o processo de aprendizagem ${ }^{64}$ e deve ser considerado cuidadosamente para a avaliação de diferentes métodos de aprendizagem.

A fim de explicar a complexidade dos processos que ocorrem em ambientes de aprendizagem mediada por computadores, tais como aqueles em que são utilizados jogos e simuladores computacionais, Keller ${ }^{82}$ propôs ainda a teoria da Motivação, Vontade e Desempenho (Motivation, Volition and Performance - MVP), que integra a motivação para a aprendizagem, a ação e o controle dos estudantes, além do processamento cognitivo das informações contidas em objetos de aprendizagem mediada por computadores. Esta teoria continua a enfatizar a essência da interação entre os componentes descritos no modelo ARCS.

Keller $^{82}$ afirma que o resultado da interação entre os componentes do modelo ARCS auxilia o estudante a iniciar a sequência de definição de metas que é fundamental para os processos de aprendizagem. Primeiramente é necessário que o estudante tenha um nível suficiente de curiosidade para 
INTRODUÇÃO

explorar a tarefa de aprendizagem (atenção); em seguida deve compreender o valor da tarefa de aprendizagem (relevância); depois deve avaliar a probabilidade de alcançar sucesso em seu desempenho na tarefa de aprendizagem (confiança), para identificar a meta relacionada ao seu desempenho. Esses componentes integram o que o autor chamou de processamento motivacional e preparam o estudante para realizar ações de acompanhamento de seu processo de aprendizagem. O quarto componente do modelo ARCS, a satisfação, está relacionada ao desempenho durante as tarefas de aprendizagem e só pode ser atingida ao final do ciclo de aprendizagem, como resultado do processamento de resultados, considerando a capacidade do estudante de refletir sobre os processos de aprendizagem.

Avaliações da motivação para a aprendizagem em ambientes de educação mediada por tecnologia têm sido realizadas por meio do uso de questionários de opinião, os quais investigam em geral a satisfação, o engajamento e a aceitação de tecnologias educacionais interativas pelos estudantes $^{50,52,72,83}$. A grande maioria desses instrumentos é composta por sentenças afirmativas e negativas referentes ao material educacional a ser avaliado pelos seus usuários, com diferentes possibilidades de resposta, dentro de padrões que seguem um modelo de escala do tipo Likert ${ }^{84}$. O número de sentenças, de possibilidades de resposta e o tipo de itens a serem avaliados 
INTRODUÇÃO

variam de acordo com cada modelo proposto, segundo a teoria na qual se baseia.

Ainda são poucos os estudos que avaliam de forma completa os aspectos relacionados à motivação para a aprendizagem, considerando todos os seus componentes ${ }^{72}$. As dificuldades relacionadas à aplicação de avaliações formais para obtenção de uma compreensão mais aprofundada sobre os aspectos relacionados à motivação para a aprendizagem não se referem somente à sua complexidade e à quantidade de itens relevantes a serem considerados, mas também à falta de suporte metodológico apropriado para a definição de indicadores e instrumentos confiáveis para sua mensuração ${ }^{85}$. Muitos estudos apresentam seus próprios questionários de avaliação da motivação (os quais são, em muitas vezes breves, simplificados e ainda não validados) baseando suas discussões nos resultados obtidos por meio da aplicação destes instrumentos. Nesses casos, é possível questionar a validade dos estudos e dos resultados obtidos, bem como refletir sobre as possibilidades de generalização destes para diferentes contextos de aprendizagem mediada por computadores.

Baseado no modelo ARCS de design motivacional existe disponível na literatura um questionário de avaliação da motivação para a aprendizagem já 
INTRODUÇÃO

validado, denominado Instructional Materials Motivation Survey $(\text { IMMS })^{76}$. Esse instrumento tem sido aplicado em diferentes contextos de aprendizagem, incluindo a aprendizagem mediada por computadores ${ }^{72,77,86-88}$. Resultados de diferentes estudos revelaram que o modelo ARCS pode ser aplicado a diversos ambientes de aprendizagem a fim de avaliar e prover maior suporte motivacional a estes ambientes ${ }^{72,77,81,86,89}$.

Em um estudo recente ${ }^{77}$ em que os dados foram coletados por meio do questionário IMMS após sua validação, dentro de um contexto educacional no qual foi utilizado um jogo computacional online, os resultados revelaram um modelo significativo em que os componentes do modelo ARCS de design motivacional são divididos entre o processamento motivacional (atenção, relevância e confiança) e o processamento de resultados (satisfação). Os autores enfatizam que ambos os processamentos devem ser considerados quando são desenvolvidos e aplicados objetos educacionais mediados por computadores.

Com relação à avaliação da motivação para a aprendizagem referente ao uso de simuladores computacionais foi encontrado apenas um estudo que avaliou o grau de motivação com o questionário IMMS na área de estatística ${ }^{86}$. Contudo, três estudos ${ }^{89-91}$ (sendo dois na área de Medicina e um na 
INTRODUÇÃO

área de Enfermagem) aplicaram cursos baseados em computadores em que 0 grau de motivação dos estudantes foi avaliado por meio do questionário IMMS. Os cursos continham cenários clínicos com informações de pacientes e questões a eles relacionadas a serem solucionadas pelos estudantes. No primeiro estudo ${ }^{89}$ os estudantes foram comparados quanto aos tipos de cursos baseados em computadores utilizados e sua correlação com seu grau de motivação e não foram encontradas diferenças significantes entre eles. Nos demais estudos ${ }^{90,91}$ compararam o uso dos cursos baseados em computadores com aulas tradicionais (face-a-face). Não foram identificadas diferenças significativas no grau de motivação dos estudantes a partir do uso de ambos os métodos de aprendizagem. Investigações detalhadas sobre o grau de motivação de estudantes por meio do uso de simuladores computacionais e de ambientes baseados em computadores segundo o modelo ARCS ainda são escassas na literatura e novos estudos devem ser conduzidos, sobretudo na área de Ciências da Saúde.

Embora diversos estudos discorram sobre a avaliação da motivação para aprendizagem, é possível identificar a necessidade da realização de novos estudos controlados, que utilizem questionários validados para a obtenção de seus resultados, a fim de se compreender melhor os processos relacionados à motivação para a aprendizagem mediada por computadores. No presente estudo a avaliação da motivação para a aprendizagem foi baseada no 
INTRODUÇÃO

modelo ARCS de design motivacional, com uso do questionário IMMS ${ }^{76}$. Em relação a esse modelo, existe uma lacuna na literatura no que se refere a estudos que investiguem o processamento motivacional por meio da análise dos componentes ARCS como um todo ${ }^{72}$. É importante ressaltar ainda que na área de Fonoaudiologia não existem estudos publicados que tenham avaliado formalmente a motivação para a aprendizagem de estudantes de graduação em contextos de aprendizagem mediada por computadores, considerando todos os seus componentes.

Com base nas considerações apresentadas nesta introdução acredita-se que a aplicação de dois métodos de aprendizagem interativos diferentes, sendo o primeiro com o uso de um jogo computacional 2D e o segundo com uso de um modelo computacional 3D sobre Anatomia e Fisiologia do Sistema Miofuncional Orofacial, poderá agregar benefícios a estudantes de Fonoaudiologia, no que se refere à aprendizagem para o desempenho prático e à motivação para a aprendizagem. A comparação entre os dois métodos interativos, bem como sua comparação com um método tradicional de aprendizagem se faz necessária, a fim de verificar os benefícios de cada um dos referidos métodos e se há um método mais efetivo para a aprendizagem e motivação da população estudada. 
OBJETIVO

O objetivo do estudo consistiu na aplicação e comparação de três métodos de aprendizagem sobre Anatomia e Fisiologia do Sistema Miofuncional Orofacial, sendo: método interativo 1 (Ml1 - com uso de um jogo computacional 2D); método interativo 2 ( $\mathrm{Ml} 2$ - com uso de um modelo computacional 3D) e método tradicional (MT - com uso de textos científicos resumidos associados a imagens estáticas em 2D pertinentes), no que se refere à aprendizagem para o desempenho prático bem como à motivação para a aprendizagem de estudantes de graduação em Fonoaudiologia sobre os assuntos abordados.

Com base nos dados de literatura apresentados, as hipóteses do presente estudo são:

1. O desempenho prático será melhor primeiramente para os estudantes que participarem do método interativo com o uso do modelo computacional 3D e, em segundo lugar, para aqueles que participarem do método interativo com uso do jogo computacional 2D, quando comparados entre si e com o método tradicional de aprendizagem;

2. A motivação para a aprendizagem será maior primeiramente para os estudantes que participarem do método interativo com o uso do 
OBJETIVO

modelo computacional 3D e, em segundo lugar, para aqueles que participarem do método interativo com uso do jogo computacional 2D, quando comparados entre si e com o método tradicional de aprendizagem. 
MÉTODO

Este estudo foi realizado com estudantes do segundo ano (3ํㅗㄴ semestre) do curso de Fonoaudiologia da Faculdade de Medicina da Universidade de São Paulo (FMUSP), dentro de uma disciplina formal do curso de graduação sobre Anatomia e Fisiologia do Sistema Miofuncional Orofacial (SMFO), a qual inclui um horário de estudo complementar semanal em sala de aula.

Os procedimentos de seleção e avaliação dos participantes foram realizados após aprovação do projeto de pesquisa pelo Comitê de Ética e Pesquisa da FMUSP (Protocolo de Pesquisa № 131/14) (Anexo 1) e assinatura do termo de consentimento livre e esclarecido pelos participantes (Anexo 2).

Os critérios para inclusão dos sujeitos no estudo foram: ter concluído as disciplinas básicas de Anatomia e Fisiologia humana (previstas pelo currículo obrigatório do curso de graduação em Fonoaudiologia da FMUSP para o primeiro ano da graduação $-1^{\circ}$ e $2^{0}$ semestres) e ter proficiência em leitura e compreensão de textos em língua inglesa.

Foram selecionados 36 estudantes para serem sujeitos do estudo. Cada estudante foi alocado randomicamente em um dentre três grupos: Grupo I (Gl) - 12 estudantes os quais participaram do método interativo 1 (Ml1), com uso de 
MÉTODO

um jogo computacional 2D; Grupo II (GII) - 12 estudantes os quais participaram do método interativo 2 (MI2), com uso de um modelo computacional 3D; 12 estudantes os quais participaram do método tradicional (MT).

O método interativo 1 (Ml1) consistiu na utilização de um jogo computacional em formato de quiz, o qual é integrado ao software Anatesse $2.0^{92}$ que aborda tópicos sobre Anatomia e Fisiologia do SMFO. O software foi utilizado pelos estudantes durante o horário de estudo complementar. Para isso, os estudantes foram alocados em duplas ou trios, conforme sua escolha, e utilizaram um computador do tipo desktop para o estudo complementar. No primeiro dia de aula foi fornecido um breve tutorial para instrução dos estudantes quando ao uso do software. Os tópicos selecionados para o estudo complementar a cada semana estavam relacionados aos assuntos abordados durante cada aula expositiva ministrada na disciplina formal.

O jogo computacional interativo é composto por questões de múltipla escolha ilustradas com imagens estáticas e animações em 2D. A cada questão respondida, os estudantes receberam um feedback sobre seu desempenho na tela do notebook: Se a resposta estivesse correta, era exibida uma figura com a representação de um rosto com expressão feliz, na cor verde; se a resposta 
MÉTODO

estivesse incorreta, era exibida uma figura com a representação de um rosto com expressão triste, na cor vermelha. Ao final de cada seção do jogo era exibida a porcentagem total de acertos.

Cada parte do referido jogo foi realizada por duas vezes; na segunda jogada, após as respostas dos estudantes serem finalizadas, era fornecida a resposta correta de cada questão automaticamente, a fim de reforçar o feedback de desempenho e ampliar as possibilidades de aprendizagem dos conteúdos abordados.

O método interativo 2 (MI2) consistiu na utilização do software Primal Pictures $^{93}$, que aborda tópicos sobre Anatomia e Fisiologia em um modelo de computação gráfica 3D. O software foi utilizado pelos estudantes durante 0 horário de estudo complementar. Para isso, os estudantes foram alocados em duplas ou trios, conforme sua escolha, e utilizaram um computador do tipo desktop com acesso à internet para o estudo complementar. No primeiro dia de aula foi fornecido um breve tutorial para instrução dos estudantes quando ao uso do software. Os tópicos selecionados para o estudo complementar a cada semana estiveram relacionados aos assuntos abordados durante cada aula expositiva ministrada na disciplina formal. 
MÉTODO

O software Primal Pictures ${ }^{93}$ é um modelo computadorizado composto por imagens associadas a textos explicativos breves, animações e vídeos em computação gráfica 3D e slides com textos breves integrados, constituindo-se como um modelo dinâmico de anatomia humana 3D. O software é dividido em áreas de domínio, incluindo títulos de acordo com especialidades médicas e das demais áreas da saúde. Para o presente estudo, foram utilizadas as seguintes partes do referido software:

1. Speech Language Pathology: área destinada especificamente para estudos em Fonoaudiologia, na qual estão contidas imagens associadas a textos explicativos breves, animações, vídeos em computação gráfica 3D e slides, com textos breves integrados. Para este estudo foram utilizados, dentro dessa área, imagens e animações em 3D sobre Anatomia e Fisiologia do SMFO. Por meio de recursos do software o estudante poderia alterar a visualização das imagens estáticas, segundo o lado que desejasse visualizar; iniciar e avançar as sequências de animações e vídeos, conforme o tempo e número de vezes que julgasse necessários; incluir notas e marcações para estudo posterior. O conteúdo dessa área está disponível em Inglês; 
MÉTODO

2. $3 D$ Head (Cabeça 3D): modelo da cabeça humana (incluindo ossos, músculos, fáscias, veias, vasos linfáticos, nervos etc.), localizado dentro da ferramenta Primal Interactive Human, que apresenta seguimentos do corpo humano em 3D, permitindo a interatividade em tempo real do usuário com 0 modelo. Esse modelo permite a manipulação do usuário, que pode girar a imagem em $360^{\circ}$; alterar a visualização segundo o lado ou ângulo que deseja visualizar; incluir notas e marcações para estudo posterior; exibir ou ocultar informações, dando ênfase a cada parte de seu estudo individual. Esse modelo está disponível em Inglês e Português;

3. Interactive learning activities for Speech-Language Pathology: essa parte da ferramenta Primal Pictures contém tópicos de revisão e um jogo em formato de quiz com questões de múltipla escolha sobre cada um dos itens selecionados para estudo. A cada semana, nos últimos 15 minutos do horário de estudo complementar, os estudantes do MI2 realizaram a revisão do estudo e responderam às questões do quiz. A cada questão respondida, os estudantes receberam um feedback sobre seu desempenho na tela do computador: uma caixa de texto aparecia na tela informando se a resposta fornecida estava correta ou incorreta e em seguida era apresentada a resposta correta (em ambas as situações), a fim de reforçar o feedback de desempenho e ampliar as possibilidades de aprendizagem dos conteúdos abordados. Ao final de cada seção do jogo era exibida a porcentagem total de acertos. O conteúdo dessa área está disponível em Inglês. 
MÉTODO

O método tradicional consistiu na utilização de textos científicos resumidos associados a figuras $2 \mathrm{D}$ estáticas pertinentes, sobre Anatomia e Fisiologia do SMFO, durante o horário de estudo complementar. Os estudantes foram orientados a realizar seu estudo da maneira que habitualmente o fazem, podendo ser individualmente, em duplas ou em trios, dentro da sala de aula. Os tópicos selecionados para o estudo complementar a cada semana estavam relacionados aos assuntos abordados durante cada aula expositiva ministrada na disciplina formal.

A aplicação dos métodos de aprendizagem foi realizada durante sete semanas, tempo de duração total da disciplina formal. As aulas expositivas para ambos os grupos tiveram duração de três horas e os horários de estudo complementar tiveram duração de uma hora. Os conteúdos abordados tanto nas aulas expositivas como nos horários de estudo complementar foram os mesmos para todos os grupos. Cada um dos grupos contou com um tutor que o acompanhou durante o horário de estudo complementar.

\section{Avaliação de desempenho prático}

Como parte da avaliação da disciplina formal é prevista a realização de uma prova prática. Nessa prova os estudantes devem responder a questões sobre procedimentos a serem realizados durante a avaliação fonoaudiológica 
MÉTODO

do Sistema Miofuncional Orofacial. As questões se referem ao desempenho dos estudantes durante a avaliação clínica do paciente relacionada aos tópicos propostos para avaliação no protocolo de Avaliação Miofuncional Orofacial com escores expandido (AMIOFE-E) ${ }^{94}$, bem como procedimentos relacionados à ética profissional (apresentação pessoal, abordagem e acomodação do paciente para realização do procedimento) e à paramentação (uso adequado do jaleco, de luvas e de outros materiais necessários para a avaliação).

Os estudantes se apresentam em duplas para essa avaliação (estudante 1 e estudante 2), contudo são avaliados individualmente. $O$ estudante 1 se apresenta à banca examinadora (composta por três fonoaudiólogos especializados na área de Motricidade Orofacial, sendo um doutor e dois mestres) e inicialmente sorteia o tópico sobre o qual será avaliado. Em seguida o estudante 1 explica à banca qual será o procedimento realizado para a avaliação, segundo preconizado no protocolo AMIOFE-E ${ }^{94}$, e como o realizará. Por fim, o estudante 1 aplica o procedimento no estudante 2, que simula ser seu paciente. Ao final da prova do estudante 1 , inicia-se a prova do estudante 2, que sorteará um novo tópico sobre o qual será avaliado conforme metodologia descrita e aplicada com o estudante 1 , sendo este seu simulador de paciente. 
MÉTODO

O desempenho dos estudantes na prova prática (nota entre 0 e 10) foi também utilizado para as comparações entre os grupos no presente estudo, a fim de verificar se há diferença nos desempenho dos estudantes de acordo com os métodos de aprendizagem aos quais foram submetidos (Ml1, Ml2 ou MT).

Avaliação da motivação para a aprendizagem

Para avaliar a motivação dos estudantes, para ambos os grupos, foi aplicado o questionário Instructional Material Motivational Survey (IMMS) ${ }^{76}$ imediatamente após a conclusão da aplicação dos dois métodos de aprendizagem. O IMMS é um instrumento de avaliação motivacional baseado no modelo $A R C S^{78,79}$, o qual foi previamente validado em um ambiente de aprendizagem mediada por computadores ${ }^{76}$. Esse instrumento tem sido aplicado para a avaliação motivacional de materiais instrucionais, especialmente em ambientes interativos de aprendizagem, incluindo ambientes mediados por computadores e jogos computacionais educacionais ${ }^{72,77,86,95}$.

O IMMS é um instrumento que contém 36 sentenças cujas possibilidades de julgamento (alternativas) são apresentadas com uma escala do tipo Likert. É solicitado que os usuários julguem cada afirmação conforme as seguintes alternativas: 1 = não é verdadeiro; 2 = ligeiramente verdadeiro; 
MÉTODO

$3=$ moderadamente verdadeiro; $4=$ na maior parte verdadeiro; $5=$ muito verdadeiro. Cada sentença do instrumento original foi desenvolvida com base nos componentes individuais do modelo ARCS de design motivacional, sendo: 12 sentenças que medem a atenção; 9 sentenças que medem a relevância; 9 sentenças que medem a confiança; e 6 sentenças que medem a satisfação do usuário.

Todas as 36 sentenças originais do IMMS foram aplicadas, tendo sido realizadas a tradução para o Português e pequenas modificações, a fim de adequá-las de acordo com os materiais instrucionais a serem aplicados (Anexo 3). A realização desse tipo de revisão é recomendada na literatura ${ }^{76}$. A estrutura gramatical original de cada sentença foi mantida para se alinhar com as questões de pesquisa.

Comparações entre o grau de motivação para a aprendizagem e os resultados obtidos na avaliação de desempenho prático

Análises específicas foram realizadas a fim de verificar se os sujeitos com maior grau de motivação, conforme avaliados pelo questionário IMMS e posteriormente classificados como apresentando baixo grau de motivação e alto grau de motivação, obtiveram melhores resultados na avaliação de desempenho prático. Essa comparação foi realizada tanto por meio de análises 
MÉTODO

intragrupo como e análises independentes do grupo do qual os estudantes foram participantes.

\section{Análise dos dados}

Os dados coletados foram submetidos à análise estatística no software SPSS versão 21. O nível de significância adotado para este estudo foi de 5\%.

Para a caracterização dos sujeitos da pesquisa o gênero foi descrito pelo número de sujeitos e pela porcentagem equivalente, e a idade foi descrita pela média, desvio-padrão, mínimo, máximo, mediana e quartis. A ANOVA de um fator foi utilizada para comparar as idades nos grupos.

Para os demais aspectos analisados no estudo as análises descritivas também foram realizadas utilizando-se os valores de média, desvio-padrão, mínimo, máximo, mediana e quartis. A comparação entre os grupos no que se refere à pontuação obtida na avaliação de desempenho foi realizada pela ANOVA seguida pelo teste post hoc de Tukey.

O questionário IMMS de avaliação da motivação possui quatro componentes diferentes sendo que cada um deles apresenta as pontuações 
MÉTODO

mínima e máxima possíveis distintas (considerando-se o número de sentenças que são utilizadas para avaliar cada componente). Dessa maneira, foi necessário realizar inicialmente uma padronização dos dados para comparar os quatro componentes em cada grupo. O z score foi utilizado para esta conversão, ou seja, a pontuação de cada sujeito foi subtraída da média geral para aquele domínio e o valore resultante foi dividido pelo desvio-padrão geral. Assim, um z score igual a 0 corresponde a um valor equivalente à média da população enquanto outros valores associados ao sinal de negativo ou positivo indicam quantos desvio-padrão aquele valor está abaixo ou acima da média.

A partir dos dados obtidos foi realizada a comparação dos domínios por meio da ANOVA de medidas repetidas de um fator em cada grupo.

A comparação entre os grupos no que se refere à pontuação geral e por componente obtida na avaliação da motivação foi realizada pela ANOVA seguida pelo teste post hoc de Tukey.

Para a comparação do desempenho dos sujeitos referente ao grau de motivação e os resultados obtidos na avaliação de desempenho prático, de acordo com o grupo, foi utilizado o teste de Mann-Whitney. Para a mesma comparação, considerando os dados independente do grupo foi utilizado o teste $t$ independente. 
RESULTADOS

Os resultados do presente estudo serão apresentados no formato de um diagrama, sete tabelas e seis gráficos, os quais representam: a distribuição dos sujeitos da pesquisa; a caracterização dos sujeitos quanto ao gênero e a idade; - desempenho dos grupos na avaliação de desempenho prático; o desempenho dos grupos na avaliação da motivação para a aprendizagem; e os resultados da comparação entre o grau de motivação dos estudantes e seus resultados na avalição de desempenho prático.

Neste estudo 36 estudantes foram selecionados por meio de sorteio aleatório para serem participantes, tendo sido alocados randomicamente em um dentre três grupos, conforme ilustra a Figura 1.

Figura 1. Dados da distribuição dos participantes do estudo

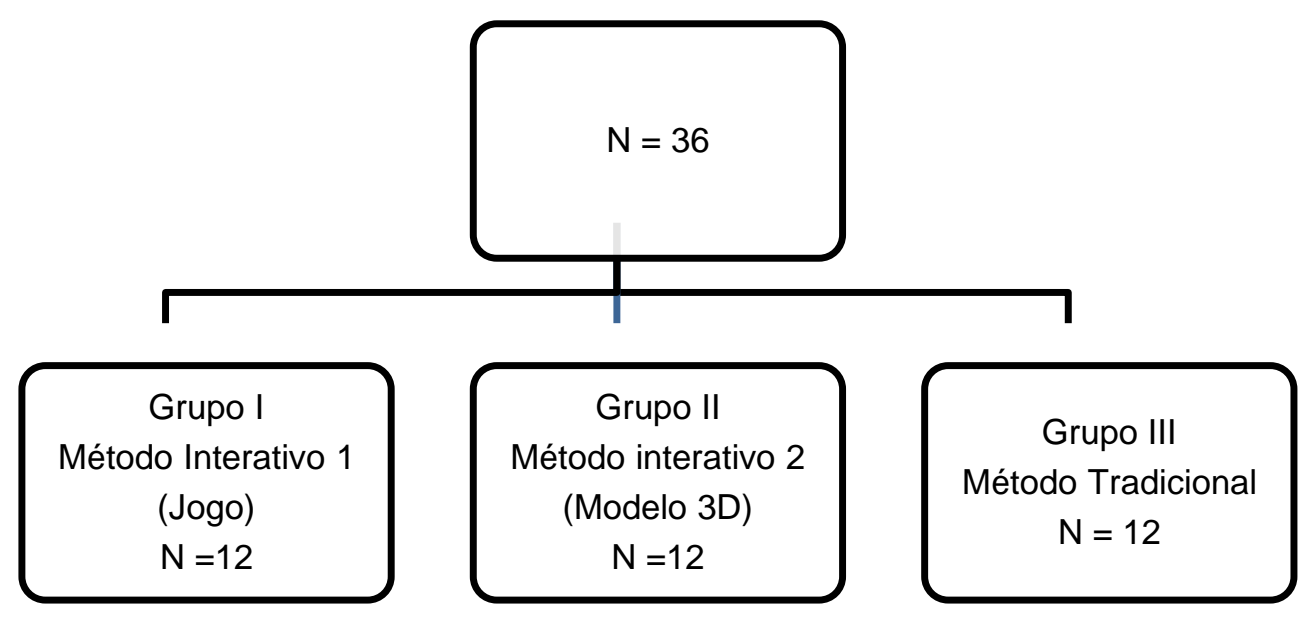


RESULTADOS

Em todos os grupos houve predomínio de sujeitos do gênero feminino, sendo que apenas no GI (MI1) não houve nenhum sujeito do gênero masculino (Tabela 1). A média geral de idade dos sujeitos foi de $22,0( \pm 4,7)$ anos e não foi observada diferença estatística entre as idades nos grupos $\left(F_{2,33}=60,72\right.$ $\mathrm{p}=0,260)$ (Tabela 2).

Tabela 1. Distribuição de frequência do gênero por grupo.

\begin{tabular}{cccccc}
\hline \multirow{2}{*}{ Grupo } & \multicolumn{3}{c}{ Gênero } & \multirow{2}{*}{ Total } \\
\cline { 2 - 5 } & $\mathrm{n}$ & $\%$ & $\mathrm{n}$ & $\%$ & \\
\hline GI(MI1) & 0 & 0,0 & 12 & 100,0 & 12 \\
GII(MI2) & 1 & 8,3 & 11 & 91,7 & 12 \\
GIII(MT) & 2 & 16,7 & 10 & 83,3 & 12 \\
\hline Geral & 3 & 8,3 & 33 & 91,7 & 36 \\
\hline
\end{tabular}

Tabela 2. Estatística descritiva da idade dos sujeitos.

\begin{tabular}{cccccccc}
\hline Grupo & Média & Desvio-Padrão & Mínimo & Máximo & Mediana & 1ํquartil & 30 quartil \\
\hline GI(MI1) & 23,2 & 6,8 & 18 & 41 & 20,5 & 19,0 & 26,8 \\
GII(MI2) & 20,2 & 1,5 & 18 & 23 & 20,0 & 19,0 & 21,5 \\
GIII(MT) & 22,6 & 4,1 & 18 & 31 & 21,5 & 20,0 & 24,8 \\
\hline Geral & 22,0 & 4,7 & 18 & 41 & 20,0 & 19,0 & 23,0 \\
\hline
\end{tabular}

Resultados da comparação entre grupos para a avaliação de desempenho prático

Para todos os grupos do estudo a pontuação média máxima na avaliação de desempenho prático foi 10. Entretanto, foram identificadas diferenças referentes à pontuação média mínima dos grupos, que para os 
RESULTADOS

grupos GI (Ml1) e GIII (MT) foi 4, enquanto para o GII (MI2) foi 6 (Tabela 3). Apesar da média de desempenho do Gll (MI2) ser maior que a dos demais, não houve diferença estatisticamente significante entre os grupos $\left(F_{2,33}=3,76\right.$ $\mathrm{p}=0,583)$, conforme ilustrado no Gráfico 1.

Tabela 3. Estatística descritiva do desempenho na prova prática por grupo.

\begin{tabular}{cccccccc}
\hline Grupo & Média & Desvio-Padrão & Mínimo & Máximo & Mediana & 1ㅇ quartil & 3o quartil \\
\hline GI(MI1) & 7,69 & 2,026 & 4 & 10 & 8,13 & 6,06 & 9,44 \\
GII(MI2) & 8,46 & 1,233 & 6 & 10 & 9,00 & 7,25 & 9,00 \\
GIII(MT) & 7,92 & 2,157 & 4 & 10 & 8,63 & 6,38 & 9,69 \\
\hline
\end{tabular}

Gráfico 1. Comparação entre a pontuação média dos grupos na avaliação de desempenho prático.

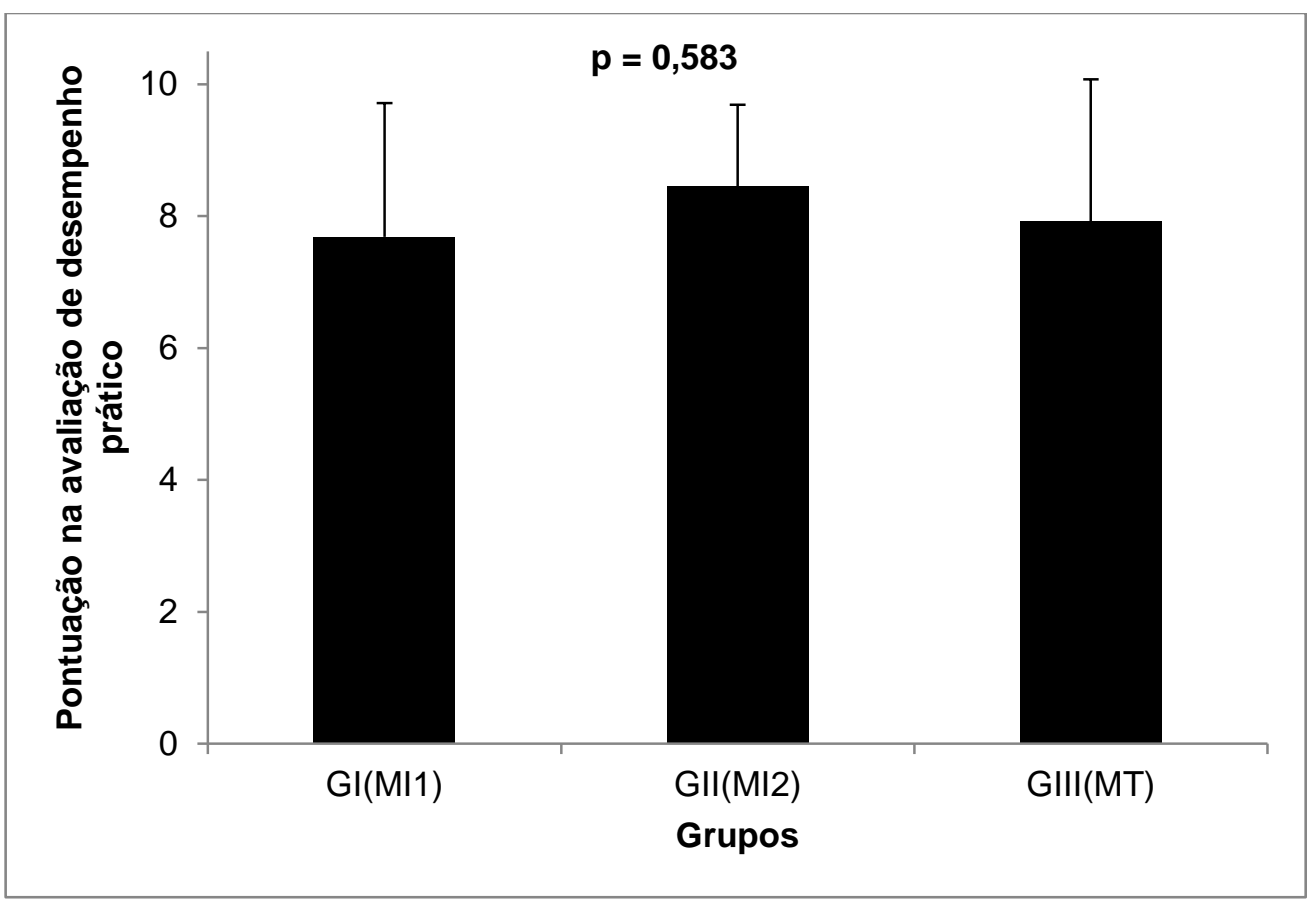


RESULTADOS

Resultados da comparação entre os quatro domínios específicos do questionário IMMS de avaliação da motivação (atenção, confiança, relevância e satisfação) em cada grupo

Foi possível notar que no Gl (Ml1) a pontuação média nos domínios ficou próxima à média da população, sendo que apenas o componente relevância apresentou pontuação mais variante. No Gll (MI2) todas as pontuações foram positivas e com média acima de 0,5. O GIII (MT) apresentou apenas pontuações médias negativas e, com exceção da relevância, estas estavam situadas abaixo de 0,5. Entretanto, nenhum dos grupos apresentou diferença estatisticamente significante entre o z score dos componentes da motivação (Gráfico 2).

Gráfico 2. Comparação entre os domínios do questionário de motivação em cada grupo.

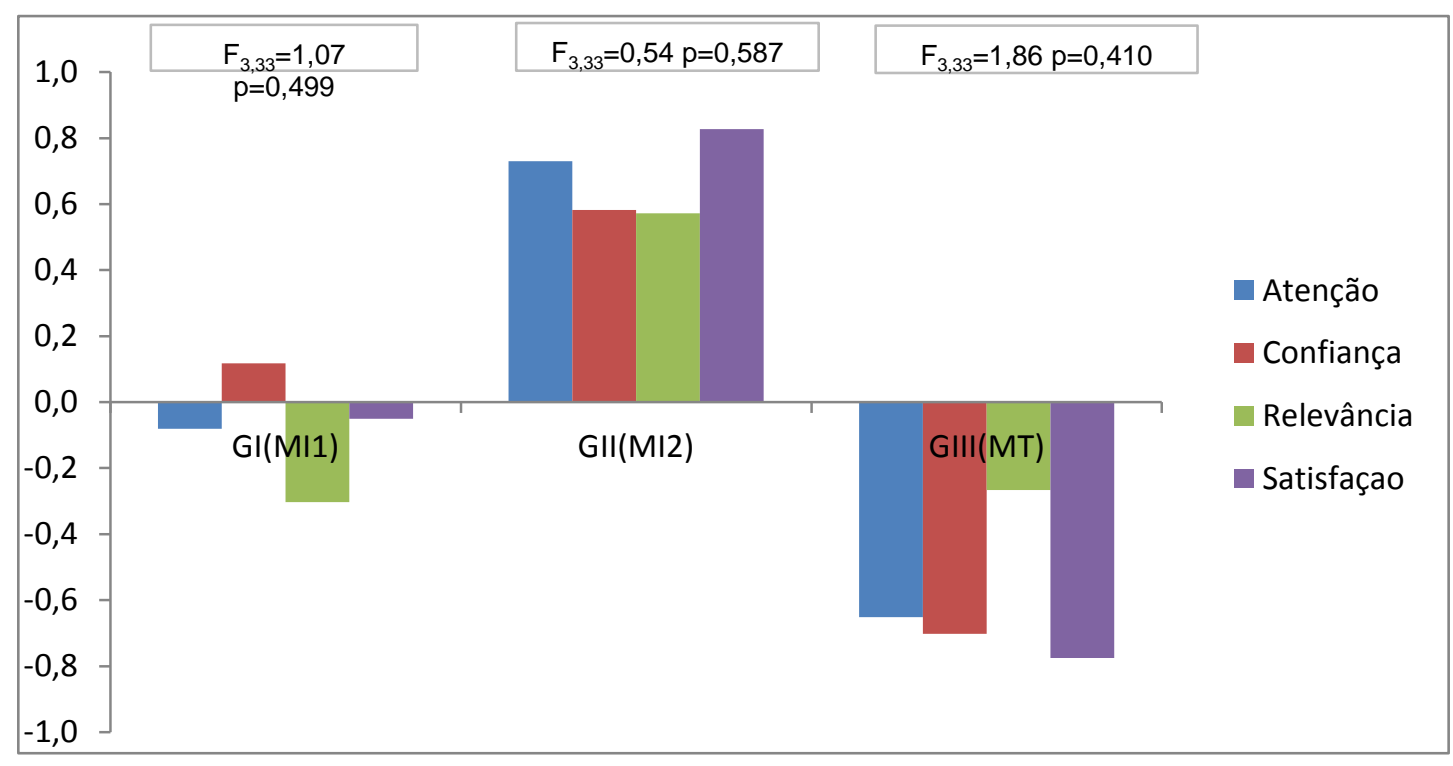


RESULTADOS

Resultados da comparação entre grupos para a avaliação da motivação para a aprendizagem

Os três grupos diferiram tanto na pontuação total como na pontuação atribuída para cada um dos aspectos da motivação avaliados por meio das respostas dos estudantes ao questionário IMMS, conforme demonstrado por meio das análises estatísticas descritiva (Tabela 4) e inferencial (Gráfico 3). A pontuação total foi maior para o GII (MI2) e a pontuação máxima para cada um dos quatro aspectos foi diferente para todos os grupos, sendo que o GII (MI2) atingiu a maior pontuação para os aspectos atenção, confiança e satisfação. No que se refere ao aspecto relevância, Gl (Ml1) e Gll (Ml2) atingiram a mesma pontuação máxima. 
RESULTADOS

Tabela 4. Estatística descritiva da pontuação no questionário IMMS por grupo.

\begin{tabular}{|c|c|c|c|c|c|c|c|c|}
\hline Aspecto & Grupo & Média & Desvio-Padrão & Mínimo & Máximo & Mediana & $1^{\circ}$ quartil & 3ำ quartil \\
\hline & GI(MI1) & 33,67 & 4,030 & 25 & 38 & 35,50 & 32,00 & 36,00 \\
\hline \multirow[t]{3}{*}{ Atenção } & GII(MI2) & 37,33 & 3,985 & 31 & 44 & 37,50 & 33,50 & 39,75 \\
\hline & GIII(MT) & 31,08 & 3,397 & 25 & 39 & 31,00 & 29,00 & 32,75 \\
\hline & GI(MI1) & 25,33 & 2,387 & 21 & 29 & 26,00 & 23,00 & 27,00 \\
\hline \multirow[t]{3}{*}{ Confiança } & GII(MI2) & 27,42 & 3,704 & 22 & 33 & 27,50 & 23,25 & 30,75 \\
\hline & GIII(MT) & 21,67 & 5,087 & 14 & 31 & 21,50 & 18,00 & 25,25 \\
\hline & GI(MI1) & 28,33 & 4,459 & 21 & 39 & 29,00 & 24,75 & 29,75 \\
\hline \multirow[t]{3}{*}{ Relevância } & GII(MI2) & 32,33 & 3,939 & 27 & 39 & 31,50 & 29,00 & 35,50 \\
\hline & GIII(MT) & 28,50 & 4,462 & 21 & 35 & 29,00 & 24,50 & 32,00 \\
\hline & GI(MI1) & 16,83 & 4,239 & 9 & 28 & 16,50 & 15,25 & 17,75 \\
\hline \multirow[t]{3}{*}{ Satisfação } & GII(MI2) & 21,67 & 4,250 & 15 & 30 & 21,00 & 19,25 & 24,75 \\
\hline & GIII(MT) & 12,83 & 4,239 & 7 & 19 & 11,50 & 9,25 & 17,75 \\
\hline & GI(MI1) & 104,17 & 10,978 & 86 & 129 & 103,50 & 97,25 & 109,75 \\
\hline \multirow[t]{2}{*}{ Total } & GII(MI2) & 118,75 & 13,363 & 102 & 144 & 117,00 & 108,75 & 128,75 \\
\hline & GIII(MT) & 94,08 & 11,595 & 78 & 109 & 94,00 & 81,75 & 106,25 \\
\hline
\end{tabular}


RESULTADOS

Gráfico 3. Comparação entre a pontuação média total dos grupos no questionário de motivação.

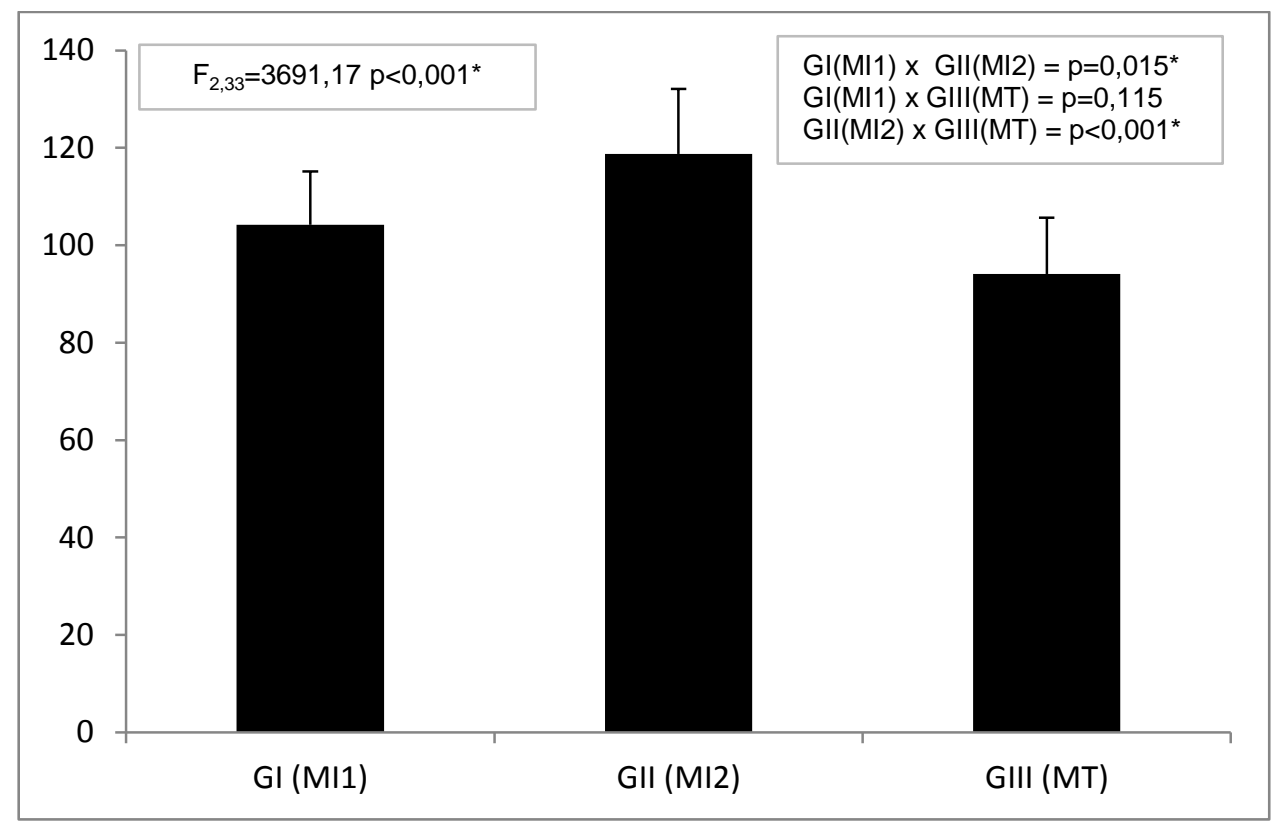

Ainda na comparação entre grupos foi possível verificar que com relação aos aspectos atenção e confiança, os grupos Gl (Ml1) e Gll (MI2) não diferiram, assim como o GI (MI1) não diferiu do GIII (MT); contudo o GII (MI2) apresentou maior pontuação que o GIII (MT) para ambos os aspectos. Com relação à relevância, apesar de ter havido diferença na ANOVA $\left(F_{2,33}=122,89\right.$ $p=0,048$ ), na comparação par a par essa diferença não foi confirmada. No que se refere à satisfação o GII (MI2) apresentou maior pontuação que os demais e o Gl (Ml1) não diferiu do GIII (MT) (Gráfico 4). 
RESULTADOS

Gráfico 4. Comparação entre a pontuação média dos grupos nos diferentes aspectos do questionário IMMS.

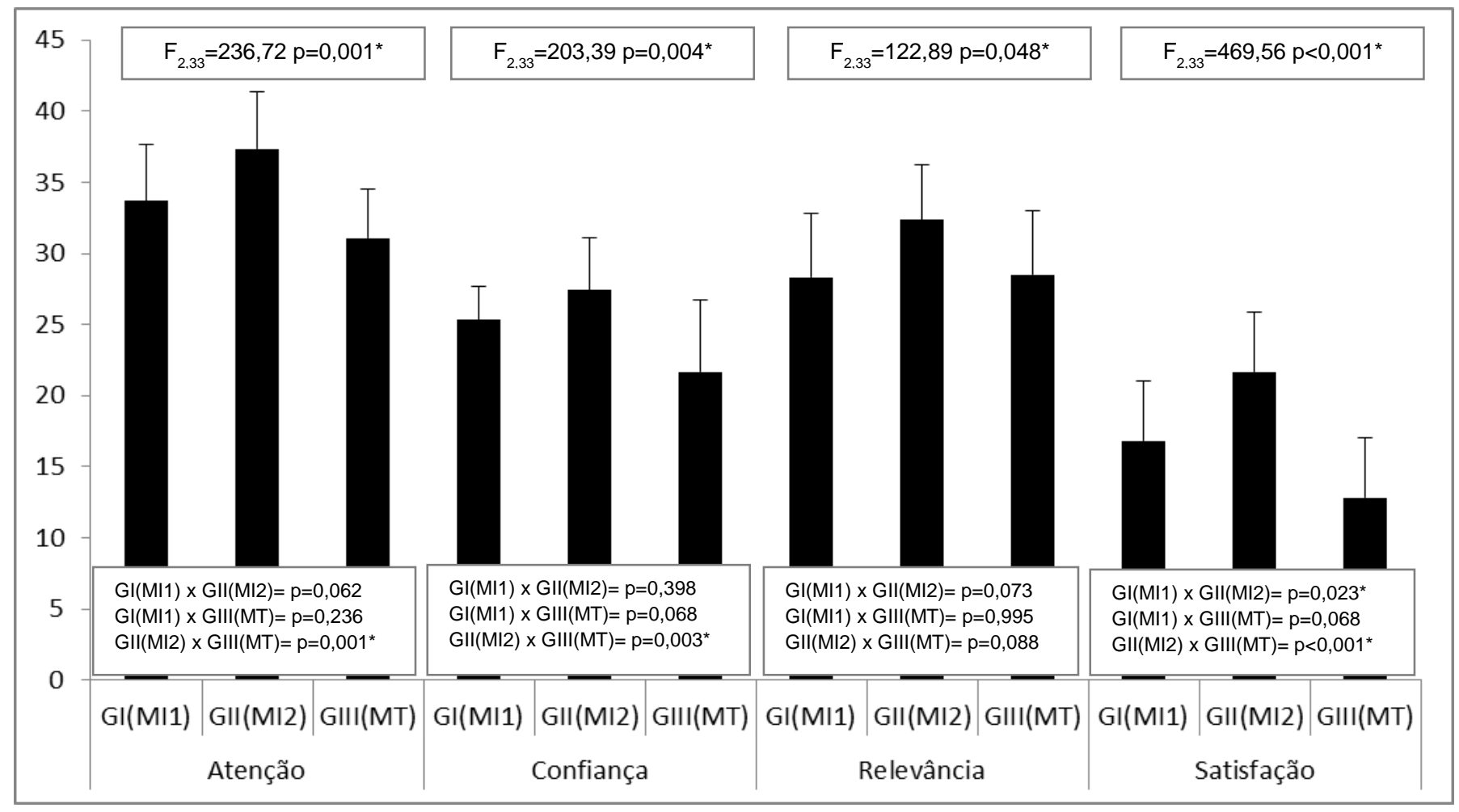

Comparação entre o grau de motivação e os resultados na avaliação de desempenho prático de acordo com o grupo

Análises específicas foram realizadas para verificar se os estudantes mais motivados dentro de cada grupo foram os que obtiveram os melhores resultados na avaliação de desempenho prático. Para classificar os sujeitos de acordo com sua motivação, a mediana da pontuação no questionário IMMS foi utilizada (mediana=105 pontos). Os sujeitos com pontuação inferior à mediana 
RESULTADOS

foram classificados com baixo grau de motivação e os sujeitos com pontuação igual ou superior à mediana foram classificados com alto grau de motivação.

A análise descritiva sugeria que os sujeitos com baixo grau de motivação apresentavam menor pontuação (Tabela 5), porém não houve diferença estatística entre os sujeitos com baixo e alto grau motivação em nenhum dos métodos de estudo $(\mathrm{Gl}=\mathrm{p}=0,810 ; \mathrm{Gll}=\mathrm{p}=0,576 ; \mathrm{Glll}=\mathrm{p}=0,926)$ (Gráfico 5).

Tabela 5. Estatística descritiva dos resultados obtidos na avaliação de desempenho prático de acordo com o grau de motivação, considerando os diferentes grupos.

\begin{tabular}{cccccccccc}
\hline \multirow{2}{*}{ Grupo } & Motivação & $\mathrm{n}$ & Média & Desvio-Padrão & Mínimo & Máximo & Mediana & 10 quartil & 3o quartil \\
\hline \multirow{2}{*}{ GI(MI1) } & Baixa & 6 & 7,50 & 1,864 & 5 & 10 & 7,25 & 5,94 & 9,44 \\
& Alta & 6 & 7,88 & 2,339 & 4 & 10 & 9,00 & 5,50 & 9,56 \\
\hline \multirow{2}{*}{ GII(MI2) } & Baixa & 2 & 8,00 & 1,414 & 7 & 9 & 8,00 & 7,00 & - \\
& Alta & 10 & 8,55 & 1,257 & 6 & 10 & 9,00 & 7,75 & 9,25 \\
\hline \multirow{2}{*}{ GIII(MT) } & Baixa & 9 & 8,03 & 1,974 & 4 & 10 & 8,25 & 6,75 & 9,63 \\
& Alta & 3 & 7,58 & 3,126 & 4 & 10 & 9,00 & 4,00 & \\
\hline
\end{tabular}


RESULTADOS

Gráfico 5. Comparação dos resultados obtidos na avaliação de desempenho prático de acordo com o grau de motivação em cada grupo.

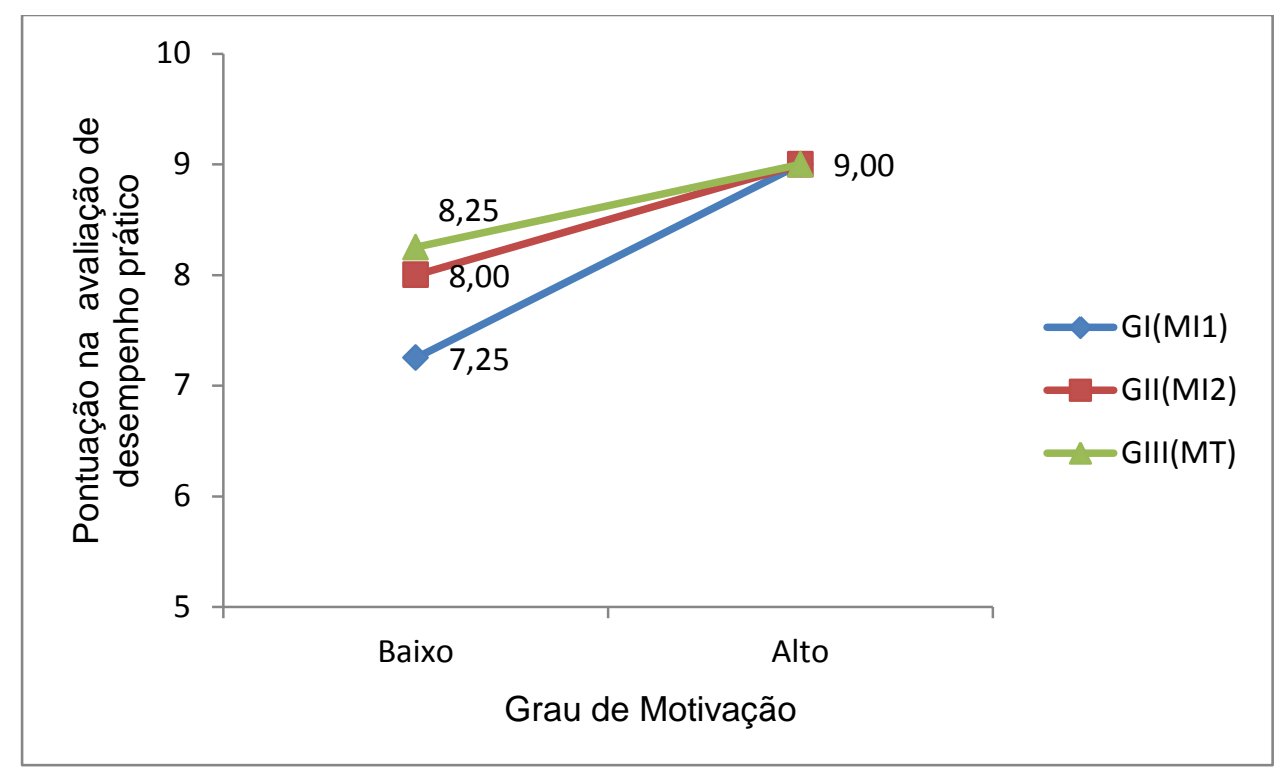

Comparação entre o grau de motivação e os resultados na avaliação de desempenho prático independente do grupo

Em virtude do reduzido número de sujeitos em cada grupo, optou-se também por fazer uma análise da comparação entre o grau de motivação dos sujeitos e os resultados obtidos na avaliação de desempenho prático, independente do grupo do qual foram participantes. Desse modo, pretendeu-se verificar se os estudantes mais motivados, independente do grupo do qual foram participantes, foram os que obtiveram melhor desempenho na avaliação de desempenho prático. Para classificar os sujeitos de acordo com seu grau de 
RESULTADOS

motivação foram utilizados os mesmos critérios adotados inicialmente para as análises de acordo com o grupo.

Foi possível observar que no Gl (Ml1) a divisão entre sujeitos com baixo e alto grau de motivação foi igual, porém no Gll (MI2) houve predomínio de sujeitos com alto grau de motivação (83,3\%) e no GIII (MT) houve predomínio de sujeitos com baixo grau de motivação $(75,0 \%)$, conforme apresentado na Tabela 6.

Tabela 6. Distribuição de frequência do grau de motivação por grupo.

\begin{tabular}{cccccc}
\hline Grupo & \multicolumn{5}{c}{ Grau de Motivação } \\
& $\mathrm{n}$ & $\%$ & $\mathrm{n}$ & $\%$ & \\
& Baixo & & \\
\hline Gl(Ml1) & 6 & 50,0 & 6 & 50,0 & 12 \\
GII(MI2) & 2 & 16,7 & 10 & 83,3 & 12 \\
GIII(MT) & 9 & 75,0 & 3 & 25,0 & 12 \\
\hline Geral & 17 & 47,2 & 19 & 52,8 & 36 \\
\hline
\end{tabular}

Ao verificar os resultados obtidos na avaliação de desempenho prático, comparando-se os sujeitos com baixo e alto grau de motivação, foi possível notar que apesar da média dos sujeitos com alto grau de motivação ser discretamente maior para os sujeitos com alto grau de motivação (Tabela 7), não houve diferença estatística entre eles (Gráfico 6). 
RESULTADOS

Tabela 7. Estatística descritiva dos resultados obtidos na avaliação de desempenho prático de acordo com o grau de motivação, independente do método de aprendizagem.

\begin{tabular}{ccccccccc}
\hline Motivação & $\mathrm{N}$ & Média & Desvio-Padrão & Mínimo & Máximo & Mediana & 1ํquartil $^{30}$ quartil \\
\hline Baixo & 17 & 7,84 & 1,796 & 4 & 10 & 8,00 & 6,63 & 9,38 \\
Alto & 19 & 8,18 & 1,887 & 4 & 10 & 9,00 & 7,00 & 9,50 \\
\hline
\end{tabular}

Gráfico 6. Comparação dos resultados obtidos na avaliação de desempenho prático de acordo com o grau de motivação, independente do método de aprendizagem.

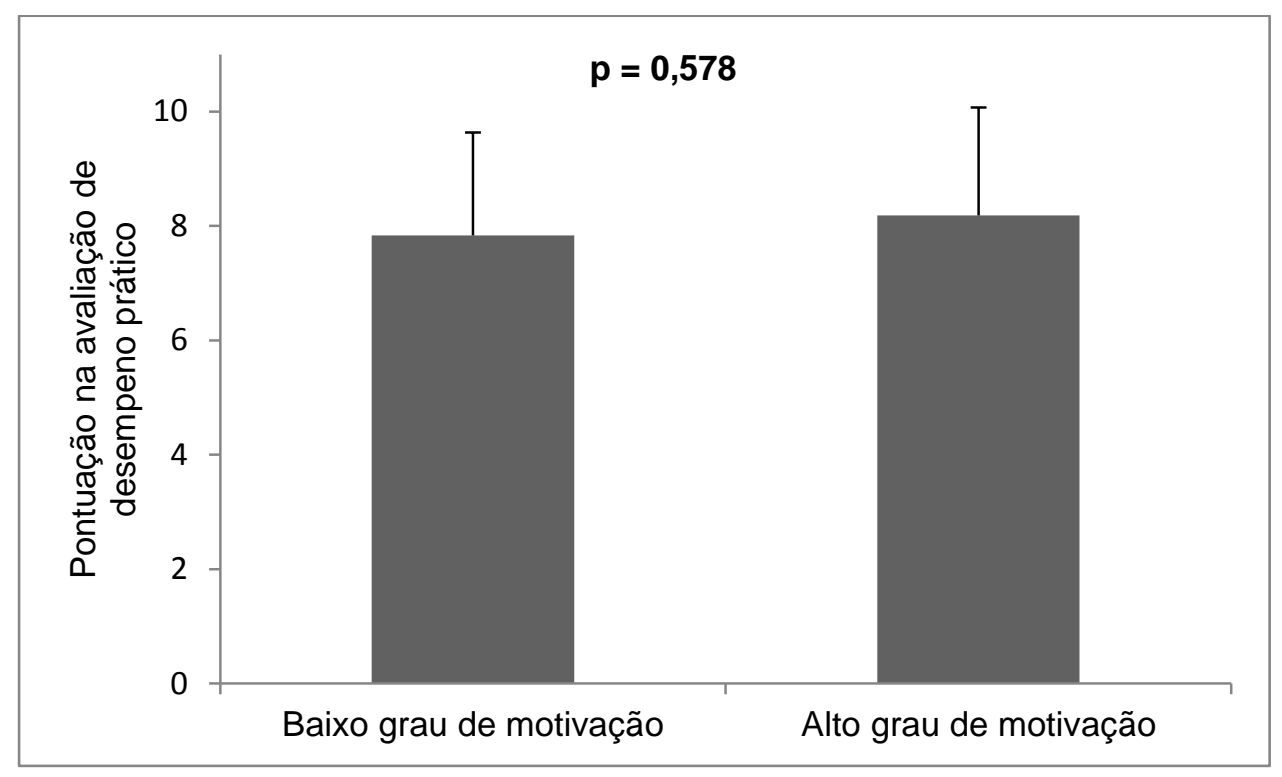




\section{DISCUSSÃO}

Neste estudo foram aplicados e comparados três métodos de aprendizagem sobre Anatomia e Fisiologia do Sistema Miofuncional Orofacial para estudantes de Fonoaudiologia, sendo dois métodos interativos (o primeiro com uso de um jogo computacional 2D e o segundo com uso de um modelo computacional 3D) e um método tradicional (com uso de textos científicos resumidos associados a figuras pertinentes). Os métodos de aprendizagem foram comparados quanto aos resultados de seus participantes para a aprendizagem medida por meio de avaliação de desempenho prático e quanto à motivação para a aprendizagem.

A primeira hipótese do presente estudo estimava que o maior grau de interatividade proporcionado pelo modelo computacional 3D, estaria associado à maior aprendizagem e melhor desempenho prático. Portanto, era esperado que os estudantes que participassem do MI2 tivessem melhor desempenho quando comparados àqueles que participassem do Ml1 e que ambos teriam melhor desempenho que os estudantes que participassem do método tradicional, os quais realizaram seus estudos de maneira mais passiva.

Os objetos educacionais propostos nos dois métodos interativos forneciam aos estudantes maiores oportunidades de iniciar tarefas de exploração dos objetos educacionais apresentados e para realizar as tomadas 
DISCUSSÃO

de decisões requeridas nas questões apresentadas. De acordo com estudos apresentados na literatura essas características estão relacionadas a maior tempo dispendido pelos estudantes para estudar, maior facilidade em manter a atenção nas tarefas de aprendizagem e maior engajamento que, consequentemente, estariam relacionados a melhores resultados em avaliações de desempenho prático ${ }^{51,96}$. Além disso, estudos sugerem que o desempenho prático deve ser melhor para estudantes e profissionais que utilizam simuladores durante a aprendizagem do que para os que se utilizam de métodos tradicionais, uma vez que proporcionam melhores oportunidades de transferência do conhecimento adquirido para a prática clínica ${ }^{97-99}$.

Embora no presente estudo os estudantes que participaram do GII (MI2) tenham obtido melhores médias na avaliação de desempenho prático, essa diferença não foi estaticamente significante quando estes sujeitos foram comparados com seus pares, participantes dos demais métodos de aprendizagem. Desse modo, os participantes dos três métodos de aprendizagem propostos apresentaram desempenho prático semelhante, não tendo sido confirmada a primeira hipótese do presente estudo.

Esses resultados podem ser explicados pelo fato de que embora no modelo computacional 3D as imagens e animações apresentem maiores 
DISCUSSÃO

detalhes referentes às estruturas e funções do Sistema Miofuncional Orofacial (SMFO), quando comparadas às imagens apresentadas nos demais métodos de aprendizagem, esses recursos não foram suficientemente relacionados a todos os procedimentos necessários para aplicação durante a avaliação de desempenho prático. Essa avaliação requeria que o estudante tivesse além do conhecimento de Anatomia e Fisiologia suficiente para avaliar as estruturas e funções do SMFO (informações que são mais bem apresentadas no Ml2), o conhecimento de alguns procedimentos específicos de avaliação, abordados em detalhes somente nas aulas expositivas e não nos métodos de aprendizagem aplicados durante o horário de estudo complementar.

Semelhante ao que foi observado no presente estudo, pesquisa recente mostrou que o desempenho prático geral de estudantes de Medicina Veterinária a partir do uso de um simulador computacional sobre ventilação mecânica foi equivalente ao desempenho de estudantes que receberam instrução somente por meio de aulas tradicionais ${ }^{52}$. O melhor desempenho a partir do uso do simulador só foi alcançado pelos estudantes que apresentaram maiores conhecimentos prévios sobre o assunto. Esse não seria o caso dos sujeitos do presente estudo, uma vez que os tópicos relacionados à prática clínica foram apresentados pela primeira vez aos três grupos igualmente, durante a as aulas da disciplina formal em que os métodos de aprendizagem propostos foram aplicados. 
DISCUSSÃO

Estudos que apresentam resultados de melhor desempenho prático para estudantes que estudam por meio de jogos ou simuladores computacionais, quando comparado ao desempenho de estudantes que utilizam métodos tradicionais de aprendizagem, têm aplicado objetos educacionais que apresentam além de informações relacionadas à Anatomia e Fisiologia, os passos para realização de procedimentos clínicos específicos ${ }^{51,97-100}$. Nos métodos interativos aplicados no presente estudo, somente as informações conceituais sobre Anatomia e Fisiologia do SMFO associadas a imagens estáticas e dinâmicas, com maior (MI2 - 3D) ou menor (Ml1 - Jogo 2D) grau de interatividade foram apresentadas aos estudantes, o que pode explicar seu desempenho semelhante ao dos estudantes que participaram do método tradicional.

A partir dos resultados da avaliação de desempenho prático e de dados apresentados na literatura é possível ponderar sobre o fato de que, principalmente os estudantes que participaram do MI2 poderiam ter obtido melhores resultados na avaliação de desempenho prático se o objeto educacional contemplasse, além de imagens estáticas e animações sobre as estruturas e funções do SMFO, tópicos relacionados a procedimentos clínicos necessários para aplicação durante a avaliação clínica fonoaudiológica. 


\section{DISCUSSÃO}

Além da análise do desempenho prático dos estudantes a partir de sua participação nos três métodos de aprendizagem propostos, foram realizadas análises relacionadas à motivação para a aprendizagem destes sujeitos. Foram consideradas análises do grau geral de motivação e também um estudo detalhado da avaliação de todos os componentes da motivação, conforme proposto no modelo ARCS de design motivacional| ${ }^{57,58}$, a partir da aplicação do questionário IMMS ${ }^{55}$.

Em geral poucos estudos têm investigado os componentes motivacionais como um todo em diferentes contextos de aprendizagem ${ }^{72}$. Além disso, trata-se de uma proposta inédita na área de Fonoaudiologia, uma vez que os poucos estudos que apresentaram análises do grau de motivação dos estudantes a partir do uso de diferentes objetos educacionais mediados por tecnologia o fizeram de forma geral e simplificada, sem considerar todos os seus aspectos e sem utilizar instrumentos validados para sua realizaçãa ${ }^{50,57,60}$.

Após a realização da padronização inicial dos dados relacionados à avaliação da motivação e sua análise de acordo com o grupo foi possível observar que, embora nenhum dos grupos tenha apresentado diferença estatisticamente significante entre o $z$ score dos componentes da motivação, os 


\section{DISCUSSÃO}

estudantes que utilizaram o jogo computacional se comportaram de maneira semelhante e com motivação próxima à média de toda a população do estudo. Já com o modelo computacional 3D os estudantes se sentiram motivados em grau acima da média da população, com resultados positivos para todos os componentes, enquanto os estudantes que participaram do método tradicional apresentaram motivação abaixo da média da população, com resultados negativos para todos os componentes.

$\mathrm{Na}$ comparação entre grupos em relação ao grau geral de motivação para a aprendizagem, os estudantes que participaram do Gll (MI2) também apresentaram os melhores resultados, sendo as diferenças estatisticamente significantes. Uma possível explicação está relacionada ao nível de interatividade apresentado pelo modelo computacional 3D, o qual é maior do que aquele apresentado pelo jogo computacional 2D e ainda maior do que 0 proporcionado pelos textos do método tradicional. Semelhante a um modelo apresentado anteriormente em estudo da área de Fonoaudiologia ${ }^{50}$, o modelo computacional 3D utilizado no presente estudo permite que o estudante manipule livremente as imagens apresentadas, podendo rotacioná-las e visualisá-las em diferentes cortes e posições, estudando mais detalhadamente cada tópico, o que não é possível realizar com os demais objetos educacionais aplicados. 
DISCUSSÃO

Nesse contexto, os resultados do presente estudo corroboram aqueles apresentados anteriormente para estudantes da área de Fonoaudiologia que aprenderam sobre anatomia do osso temporal por meio de um modelo computacional $3 D^{50}$. Esses sujeitos apresentaram maiores níveis de curiosidade durante o estudo, aumentando sua motivação para a aprendizagem e o tempo que desejaram dispender para estudar. Além disso, corroboram resultados de estudo da área de Medicina Veterinária os estudantes também se sentiram mais engajados durante o processo de aprendizagem por meio da utilização de um simulador computacional ${ }^{52}$.

Segundo a teoria $M V P^{82}$, que leva em consideração os componentes da motivação apresentados no modelo ARCS, o processamento motivacional (constituído pelos componentes: atenção, relevância e confiança) auxilia o estudante a estabelecer objetivos iniciais para seu desempenho que são críticos para sustentar o processo de aprendizagem. Em seguida, é necessário que por meio de sua vontade transforme suas intenções relacionadas à aprendizagem em ações concretas. Nesse ponto ocorre a interface entre a motivação e o processamento de informações, em que o estudante aplica estratégias metacognitivas para gerenciar ativamente sua aprendizagem. Para isso, é importante considerar a capacidade cognitiva do estudante, a qual é limitada pela memória de trabalho e que não deve ser excedida, de modo a sustentar as possibilidades de armazenamento e transferência de novas 
DISCUSSÃO

informações à memória de longo termo, criando novos modelos mentais ${ }^{72}$.

Em relação aos aspectos de atenção e confiança do processamento motivacional, a maior pontuação no questionário aplicado para a avaliação da motivação foi atribuída pelos estudantes que utilizaram 0 modelo computacional 3D. Contudo, não foi identificada diferença estatisticamente significante entre os dois métodos interativos aplicados, para esses dois componentes. A atenção se refere à resposta do estudante a um dado estímulo percebido durante o processo de aprendizagem, a qual pode levá-lo a empregar maior esforço para estudar; a confiança está relacionada à construção de uma expectativa positiva do estudante sobre a possibilidade de obter um bom desempenho a partir da interação com um determinado objeto ou tarefa de aprendizagem ${ }^{72,77-79}$. Dessa maneira, a partir dos resultados apresentados para estes dois componentes no presente estudo, foi possível observar que os dois métodos interativos propostos foram eficientes para estimular maiores níveis de atenção e confiança aos estudantes durante o processo de aprendizagem, mesmo com seus diferentes níveis de interatividade.

Tanto o jogo computacional como o modelo computacional 3D proporcionaram aos estudantes a possibilidade de resolução de questões com 


\section{DISCUSSÃO}

o fornecimento imediato de feedback sobre seus resultados. A possibilidade de realização de uma análise de desempenho, bem como o posterior fornecimento das respostas corretas, permitem que os estudantes reflitam sobre seus erros, foquem a atenção aos conteúdos mais relevantes e busquem estudar mais os conceitos que ainda precisam ser melhor aprendidos, podendo favorecer 0 processo de aquisição de conhecimento ${ }^{72,87,101}$.

No modelo computacional 3D era ainda proposto que os participantes estudassem inicialmente os conceitos de Anatomia e Fisiologia do SMFO, podendo manipular livremente as imagens e animações fornecidas, e que ao final realizassem as tarefas do quiz integrado à ferramenta. $O$ senso de liberdade durante a aprendizagem promove um sentimento de controle pessoal que faz parte do componente confiança ${ }^{85}$. Essa oportunidade de selecionar como e quando aprender, assim como a possibilidade de escolher como lidar com uma determinada tarefa, com base em suas preferências, afeta a motivação intrínseca do estudante ${ }^{102}$. Isso pode justificar o fato de que as maiores pontuações atribuídas para os aspectos atenção e confiança foram fornecidas pelos estudantes que participaram do Ml2.

Ainda sobre a avaliação dos aspectos atenção e confiança, o Ml2 demonstrou ser significativamente mais eficaz que o método tradicional dentro 
DISCUSSÃO

do processamento motivacional para a aprendizagem. Esses resultados corroboram dados da literatura que mostram que métodos tradicionais de aprendizagem que não se utilizam de ferramentas interativas complementares têm sido criticados e considerados como estratégias não efetivas para motivar os estudantes, uma vez que promovem sua passividade, resultando no baixo engajamento destes sujeitos no processo de aprendizagem ${ }^{52,103}$.

A instrução centrada no professor e orientada somente por meio de textos pode falhar no que se refere ao estímulo da aprendizagem conceitual e pode levar a não compreensão de conceitos abstratos e à manutenção de erros, em muitas vezes oriundos de conceitos abstratos mal interpretados pelos estudantes e não corrigidos ${ }^{104,105}$.

É importante considerar ainda que diferenças na habilidade de controle da atenção e de manutenção dos objetivos das informações e tarefas apresentadas ao estudante afetam o quanto pode se beneficiar de pistas visuais e das informações apresentadas durante $o$ processo de aprendizagem ${ }^{106}$. A novidade e a atratividade de ambientes de aprendizagem mediados por tecnologia estimulam a curiosidade dos estudantes e melhoram seu grau de atenção durante a aprendizagem ${ }^{86}$. Atualmente, pesquisadores da área de Psicologia Cognitiva afirmam que a capacidade de controlar o foco de 
DISCUSSÃO

atenção, relacionada à capacidade da memória de trabalho, é um importante ponto de partida para pesquisas futuras que investiguem como as diferenças relacionadas à capacidade da memória de trabalho podem afetar a aprendizagem mediada por tecnologia ${ }^{101}$.

Dentro do modelo ARCS o componente relevância do processamento motivacional representa o nível de habilidade dos estudantes em perceberem a associação entre seus conhecimentos prévios e novas informações sobre um determinado assunto. Além disso, se refere à compreensão que o estudante tem referente ao valor do objeto educacional e das tarefas de aprendizagem a ele apresentadas ${ }^{82}$. No presente estudo, não houve diferença estatisticamente significante na comparação entre os grupos com relação à avaliação desse aspecto. Assim, é possível afirmar que os estudantes atribuíram o mesmo grau de relevância aos conteúdos apresentados, independentemente do método de aprendizagem do qual fizeram parte.

O componente relevância também pode ser considerado como parte da motivação extrínseca que dirige os comportamentos dos estudantes, a qual demanda um grande suporte contextual para auxiliá-los a incorporarem os conceitos abordados em sua vida, segundo suas necessidades ${ }^{72,107}$. Embora os sujeitos deste estudo tenham atribuído valor aos objetos educacionais 
DISCUSSÃO

apresentados nos três métodos de aprendizagem sobre Anatomia e Fisiologia do SMFO, é possível que não tenham conseguido visualizar o impacto imediato dos conteúdos estudados em sua própria vida, neste caso como futuros fonoaudiólogos, diminuindo o grau de relevância desses conteúdos atribuído por eles no momento em que a avaliação de motivação foi aplicada.

Por meio da conexão entre os objetivos da aprendizagem e seus próprios interesses os estudantes são inspirados a se engajar mais ativamente no processo de aprendizagem e provocar as estratégias cognitivas mais apropriadas para a realização das tarefas oriundas deste processo ${ }^{85}$. Desse modo, conclui-se que o design e o contexto de aplicação das ferramentas propostas no presente estudo devem ser aprimorados para auxiliar os estudantes a atribuírem maior grau de relevância aos conteúdos e a transferirem o conhecimento adquirido durante a formação para sua prática clínica.

Com relação ao aspecto satisfação os estudantes que participaram do MI2, com uso do modelo computacional 3D, apresentaram a melhor avaliação, com diferença estatisticamente significante quando comparados aos estudantes dos demais grupos. A satisfação, segundo a teoria MVP, é o resultado do processamento de resultados no qual os estudantes avaliam 
DISCUSSÃO

cognitivamente a equidade entre o esforço investido e os resultados percebidos ao final do processo de aprendizagem, a partir da interação com um dado objeto educacional ${ }^{82}$. Desse modo, os estudantes analisam se vale a pena continuar investindo seu esforço no estudo de acordo com o material educacional que utilizam ${ }^{77}$.

Durante o processamento de resultados o estudante reflete sobre todos os estágios do processo de aprendizagem, emocionalmente e cognitivamente, chegando então a um determinado grau de satisfação ${ }^{72}$. Assim, de acordo com os resultados do presente estudo é possível afirmar que os estudantes que utilizaram o modelo computacional 3D avaliaram que os resultados obtidos ao final da aplicação do MI2 compensaram o esforço empregado durante o processo de aprendizagem, trazendo maior grau de satisfação a estes sujeitos ao final do processo.

Apesar de os resultados apresentados pelo grupo que participou do Ml1, com uso do jogo computacional 2D, para o processamento motivacional tenham sido semelhantes aos do grupo que utilizou o modelo computacional 3D (componentes atenção, confiança e relevância), os resultados do processamento de resultados não foram os mais satisfatórios, sendo equivalentes àqueles apresentados pelo grupo que participou do método 


\section{DISCUSSÃO}

tradicional. Um dos motivos para que isso tenha ocorrido pode estar relacionado a uma possível sobrecarga cognitiva gerada durante a interação dos estudantes com o jogo, uma vez que durante todo o horário de estudo complementar os estudantes deveriam estar respondendo às questões apresentadas no jogo. Segundo a teoria MVP, os estudantes estão vulneráveis à diminuição na motivação em virtude do cansaço que pode ser ocasionado pelo processamento cognitivo de informações para realização de determinadas tarefas $^{72}$. Entretanto, os aspectos relacionados ao esforço cognitivo empregado durante a interação com os métodos de aprendizagem propostos não foram formalmente investigados neste estudo e poderão ser objeto de estudo em pesquisas futuras.

É necessário considerar também que o jogo computacional apresentado neste estudo não é tão interativo e complexo quanto os jogos online com representações em 3D e cenários elaborados, em termos gráficos e de possibilidades de interação, os quais tem demonstrado grande potencial para motivar estudantes durante 0 processo de aprendizagem ${ }^{72,87}$. Embora 0 potencial dos jogos computacionais seja grande no que se refere à motivação para a aprendizagem e à melhora do desempenho dos estudantes no que se refere ao conhecimento adquirido por meio da interação com esse tipo de objeto educacional, ainda não existe consenso na literatura sobre como os jogos computacionais podem influenciar em cada componente motivacional 


\section{DISCUSSÃO}

descrito no modelo $\mathrm{ARCS}^{108}$. O mesmo pode ser dito sobre o estudo da motivação para a aprendizagem a partir do uso de simuladores computacionais $^{86}$.

Quanto maior o nível de motivação do estudante durante seu processo de aprendizagem maiores são as chances de estímulo do pensamento crítico e de se alcançar efeitos positivos na aprendizagem ${ }^{69}$. No presente estudo, 0 modelo computacional 3D se mostrou mais adequado para estimular a motivação dos estudantes para aprender, quando considerados os resultados da avaliação de todos os componentes motivacionais do modelo ARCS. Os estudantes apresentaram um maior grau de motivação, quando comparado ao dos demais grupos, considerado como de sucesso ${ }^{77,82}$ com relação ao processamento motivacional, com altos níveis de atenção e confiança, seguidos de moderado nível de relevância, os quais resultaram em maior grau de satisfação no processamento de resultados, confirmando a segunda hipótese deste estudo.

A fim de compreender as relações entre o grau de motivação e os resultados obtidos pelos estudantes na avaliação de desempenho prático, foram propostas análises destes resultados de acordo com o método de aprendizagem e independente do método. Foi possível observar que no Gl 
DISCUSSÃO

(MI1) a divisão entre sujeitos com baixo e alto grau de motivação foi igual, porém no Gll (MI2) houve predomínio de sujeitos com alto grau de motivação e no GIII (MT) houve predomínio de sujeitos com baixo grau de motivação.

Entretanto, os resultados mostraram que não houve diferença estatisticamente significante entre os sujeitos com baixo e alto grau motivação na avaliação de desempenho prático em nenhum dos métodos de estudo, tampouco nas análises que verificaram o desempenho dos sujeitos independente do grupo do qual foram participantes. Esses resultados são contrários àqueles apresentados em estudo recente que mostrou melhor desempenho para estudantes mais motivados os quais participaram de uma proposta de aprendizagem mediada por tecnologia com uso de jogo computacional contextualizado ${ }^{87}$. Contudo, os resultados do presente estudo foram semelhantes ao do referido estudo para os estudantes participantes de método tradicional de aprendizagem, em que diferenças no grau de motivação não resultaram em diferenças em seu desempenho prático.

Quando o grau de motivação é maior, as estratégias de autocontrole e intenção de aprender podem favorecer o desempenho dos estudantes. Contudo, é necessário considerar que embora um alto grau de motivação possa facilitar a aprendizagem efetiva, a maioria dos estudantes precisa investir esforço adicional e empregar estratégias de autocontrole para permanecerem diante de uma determinada tarefa de aprendizagem e superar 


\section{DISCUSSÃO}

diferentes tipos de distração que possam ocorrer durante o processo de aprendizagem ${ }^{86}$. No presente estudo embora os sujeitos que participaram do MI2 tenham apresentado o mais alto grau de motivação, esse fator não foi suficiente para que houvesse um melhor desempenho destes em um procedimento de avaliação fonoaudiológica clínica. É possível que o caráter inovador, sobretudo do modelo computacional 3D, tenha distraído os estudantes de seu foco de aprendizagem ou apresentado um tipo de demanda cognitiva desconhecida aos seus usuários. Com isso, embora sua curiosidade e motivação para aprender tenham sido maiores, eles se comportaram de forma semelhante aos seus pares participantes dos demais métodos de aprendizagem propostos na avaliação de desempenho prático.

Ambientes interativos que produzem um alto grau de motivação e curiosidade, nos quais é possível incluir principalmente o modelo computacional 3D segundo os resultados do presente estudo, não precisam necessariamente prover um alto grau de suporte à vontade do estudante de permanecer diante da tarefa de aprendizagem; contudo é necessário analisar cuidadosamente a demanda cognitiva apresentada ao estudante por meio de sua interação com esse tipo de objeto educacional, relacionada com o processamento de informações, importante para sua aprendizagem e desempenho ${ }^{86}$. No presente estudo, conforme mencionado anteriormente, não foram realizadas análises específicas da demanda cognitiva apresentada aos estudantes. Estudos futuros deverão considerar esse tipo de análise, a fim de 
DISCUSSÃO

compreender melhor os resultados apresentados e propor novas estratégias de aplicação para os métodos de aprendizagem aqui avaliados.

Além dos aspectos relacionados à motivação para a aprendizagem e à demanda cognitiva, é necessário considerar aqueles anteriormente mencionados referentes à falta de tópicos relacionados a procedimentos clínicos específicos nos métodos de aprendizagem propostos. Uma abordagem de aprendizagem eficaz deve considerar além do grau de interatividade e sua influência na motivação para a aprendizagem, o contexto em que o estudante está inserido e o quanto este reflete cenários reais autênticos ${ }^{87}$. Quanto maior a correspondência entre $o$ ambiente de aprendizagem e a realidade, mais 0 estudante será capaz de compreender os conceitos e procedimentos ensinados e aplicá-los em cenários da vida real ${ }^{109}$, nos quais os conhecimentos adquiridos serão requeridos na prática.

Desse modo os métodos de aprendizagem propostos no presente estudo devem ser aprimorados no que se refere à apresentação de cenários que contenham os procedimentos relacionados à prática clínica em Fonoaudiologia (sobretudo o método interativo 2, o qual demonstrou maior eficácia para estimular a motivação dos estudantes), neste caso para a avaliação do SMFO, a fim de prover maiores possibilidades de sucesso na aprendizagem e aplicação destes conceitos associados aos conceitos básicos de Anatomia e Fisiologia do SMFO. 
CONCLUSÃO

Em relação às hipóteses do estudo, a partir das análises dos resultados obtidos, pode ser concluído que:

H1. O desempenho prático será melhor primeiramente para os estudantes que participarem do método interativo com o uso do modelo computacional $3 D$ e, em segundo lugar, para aqueles que participarem do método interativo com uso do jogo computacional 2D, quando comparados entre si e com o método tradicional de aprendizagem - Essa hipótese não foi confirmada uma vez que os estudantes dos três grupos investigados obtiveram resultados semelhantes na avaliação de desempenho prático, não indicando que um modelo computacional 3D possa ser considerado superior aos demais.

H2. A motivação para a aprendizagem será maior primeiramente para os estudantes que participarem do método interativo com o uso do modelo computacional $3 D$ e, em segundo lugar, para aqueles que participarem do método interativo com uso do jogo computacional 2D, quando comparados entre si e com o método tradicional de aprendizagem - Essa hipótese foi plenamente confirmada. Os estudantes que utilizaram o modelo computacional 3D apresentaram 
CONCLUSÃO

um maior grau de motivação, quando comparados aos sujeitos dos demais grupos em relação ao processamento motivacional (com altos níveis de atenção e confiança, seguidos de moderado nível de relevância) e ao processamento de resultados (maior grau de satisfação). Em segundo lugar, o maior grau de motivação foi apresentado pelos estudantes que utilizaram o jogo computacional 2D, com relação ao processamento motivacional. Os estudantes que participaram do método tradicional foram os que apresentaram 0 menor grau de motivação referente tanto ao processamento motivacional como ao processamento de resultados. Os grupos participantes do método interativo 1 e do método tradicional não se diferenciaram quanto ao grau de satisfação. 


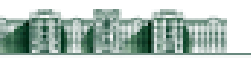 \\ MEDICINA \\ CSP \\ COMITÊ DE ÉTICA EM PESQUISA}

\section{APROVAÇÃo}

O Comitê de Ética em Pesquisa da Faculdade de Medicina da Universidade de São Paulo, em sessão de 23/o7/2014, APROVOU o Protocolo de Pesquisa no 131/14 intitulado: "EDUCAÇÃo MEDIADA POR TECNOLOGIA EM FONOAUDIOLOGIA: UMA COMPARAÇÃO ENTRE TRÊS MÉTODOS DE APRENDIZAGEM SOBRE O SISTEMA MIOFUNCIONAL OROFACIAL" apresentado pelo Departamento de FISIOTERAPIA, FONOAUDIOLOGIA E TERAPIA OCUPACIONAL

Cabe ao pesquisador elaborar e apresentar ao CEPFMUSP, os relatórios parciais e final sobre a pesquisa (Resolução do Conselho Nacional de Saúde n 466/12).

Pesquisador (a) Responsável: Claudia Regina Furquim de Andrade Pesquisador (a) Executante: Silmara Rondon Melo

CEP-FMUSP, 28 de Julho de 2014 .

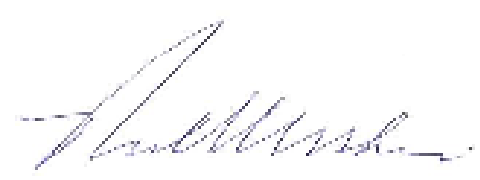

Prof. Dr. Paulo Eurípedes Marchiori Vice-Coordenador Comitê de Ética em Pesquisa 


\section{FACULDADE DE MEDICINA DA UNIVERSIDADE DE SÃO PAULO-HCFMUSP}

MODELO DE TERMO DE CONSENTIMENTO LIVRE E ESCLARECIDO

DADOS DE IDENTIFICAÇÃO DO SUJEITO DA PESQUISA OU RESPONSÁVEL LEGAL

1. NOME:

DOCUMENTO DE IDENTIDADE № :

SEXO : $\quad M \square F \square$

DATA NASCIMENTO:

ENDEREÇO

№

APTO:

BAIRRO:

CIDADE

CEP:

TELEFONE: DDD ..)

2. RESPONSÁVEL LEGAL

NATUREZA (grau de parentesco, tutor, curador etc.)

DOCUMENTO DE IDENTIDADE : SEXO: $M \square F \square$

DATA NASCIMENTO.: .....................

ENDEREÇO

№ APTO:

BAIRRO: CIDADE

CEP: TELEFONE: DDD

\section{DADOS SOBRE A PESQUISA}

1. TÍTULO DO PROTOCOLO DE PESQUISA: Educação mediada por tecnologia em Fonoaudiologia: uma comparação entre três métodos de aprendizagem sobre o Sistema Miofuncional Orofacial.

PESQUISADOR : Dra. Claudia Regina Furquim de Andrade

CARGO/FUNÇÃO: Professora Titular

INSCRIÇÃO CONSELHO REGIONAL №

UNIDADE DO HCFMUSP: Departamento de Fisioterapia, Fonoaudiologia e Terapia Ocupacional

3. AVALIAÇÃO DO RISCO DA PESQUISA:

$\begin{array}{lll}\text { RISCO MÍNIMO } & X & \text { RISCO MÉDIO } \\ \text { RISCO BAIXO } & \square & \text { RISCO MAIOR }\end{array}$

4. DURAÇÃO DA PESQUISA : 36 meses 
FACULdADE DE MEDICINA DA UNIVERSIDAdE dE SÃo PAULO-

HCFMUSP

\section{1 - Justificativa e objetivos da pesquisa}

Estamos convidando você a participar de uma pesquisa cujo objetivo é aplicar e comparar três métodos de ensino e aprendizagem sobre Anatomia e Fisiologia do Sistema Miofuncional Orofacial, sendo: método interativo 1 (com uso de um jogo computacional 2D); método interativo 2 (com uso de um modelo computacional 3D) e método tradicional (com uso de textos científicos resumidos associados a imagens em 2D pertinentes), no que se refere à aprendizagem, retenção de conhecimento e motivação para a aprendizagem de estudantes de graduação em Fonoaudiologia sobre os assuntos abordados em uma das disciplinas do curso.

Com essa pesquisa, pretende-se avaliar a possibilidade da inserção de jogos e modelos computacionais como instrumentos de apoio para o processo de ensinoaprendizagem no curso de graduação em Fonoaudiologia e os benefícios que podem ser trazidos aos estudantes pelo uso deste tipo de material (aumento do conhecimento sobre anatomia e fisiologia do SMFO, estímulo para o estudo formal, motivação para aprendizagem, entre outros).

\section{2 - Procedimentos que serão utilizados e propósitos, incluindo a identificação dos procedimentos que são experimentais}

Cada estudante será alocado em um dentre três grupos: Grupo I (Gl) - 13 estudantes os quais participarão do método interativo 1(Ml1); Grupo II (GII) - 13 estudantes os quais participaram do método interativo 2 (MI2) e Grupo III - 13 estudantes os quais participaram do método tradicional (MT).

O método interativo 1 (MI1) consistirá na utilização de um jogo computacional em formato de quiz, o qual é integrado ao software Anatesse $2.0^{34}$ que aborda tópicos sobre Anatomia e Fisiologia do SMFO. O software será utilizado pelos estudantes durante o horário de estudo complementar. Para isso, será utilizado um notebook integrado a um projetor multimídia. A cada semana um estudante será escolhido pelo grupo para operar o software (registrar as respostas do grupo às questões do jogo, utilizando o notebook). Haverá apenas um computador para utilização de todo o grupo. 
O método interativo 2 (MI2) consistirá na utilização do software Primal Pictures, que aborda tópicos sobre Anatomia e Fisiologia em um modelo de computação gráfica 3D. O software será utilizado pelos estudantes durante o horário de estudo complementar. Para isso, os estudantes serão alocados em trios, conforme sua escolha, e cada trio terá acesso a um computador do tipo desktop com acesso à internet para realizar o estudo complementar. No primeiro dia de aula será fornecido um breve tutorial para instrução dos estudantes quando ao uso do software.

O método tradicional consistirá na utilização de textos científicos resumidos associados a figuras pertinentes, sobre Anatomia e Fisiologia do SMFO, durante o horário de estudo complementar. Os estudantes serão orientados a realizar seu estudo da maneira que habitualmente o fazem, podendo ser em trios, grupo ou individualmente, dentro da sala de aula. Para todos os grupos os tópicos selecionados para o estudo complementar a cada semana estarão relacionados aos assuntos abordados durante cada aula expositiva ministrada na disciplina formal.

Antes, imediatamente e após seis meses da realização dos métodos de ensino e aprendizagem os participantes deverão responder um questionário de conhecimento, contendo questões de múltipla escolha sobre os temas abordados na disciplina e nos materiais didáticos fornecidos para cada um dos grupos, a fim de medir os conhecimentos adquiridos após a utilização destes materiais. Em outro dia, após a conclusão da aplicação dos referidos métodos de ensino e aprendizagem, será aplicado outro questionário contendo afirmativas com cinco possibilidades de resposta (em que o estudante deverá escolher apenas uma), sobre a motivação para a aprendizagem (incluindo a satisfação do estudante), referentes aos materiais didáticos fornecidos dentro do método de ensino e aprendizagem do qual tiver participado.

3 - Desconfortos e riscos esperados: A proposta deste projeto não oferece nenhum risco à saúde. Contudo, durante a atividade principal, o estudante poderá sentir-se um pouco cansado de acordo com a extensão e a complexidade dos tópicos a serem estudados durante o horário de estudo complementar, por meio dos materiais didáticos utilizados em cada um dos métodos de ensino e aprendizagem propostos.

4 - Benefícios que poderão ser obtidos: Melhora da qualidade e interatividade no processo de ensino e aprendizagem em Fonoaudiologia, ampliação e retenção de 
conhecimento do estudante sobre os assuntos abordados em curto e longo prazo e maior motivação para a aprendizagem.

5 - Garantia de acesso: Em qualquer etapa do estudo, você terá acesso aos profissionais responsáveis pela pesquisa para esclarecimento de eventuais dúvidas. $O$ principal investigador é a Profa. Dra. Claudia Regina Furquim de Andrade, que pode ser encontrado no endereço Rua Cipotânea, 51; Cidade Universitária, Butantã; São Paulo - SP; Telefone 11- 3091 8406. Se você tiver alguma consideração ou dúvida sobre a ética da pesquisa, entre em contato com o Comitê de Ética em Pesquisa (CEP) - Av. Dr. Arnaldo, 251 - Cerqueira César - São Paulo - SP -210 andar - sala 36- CEP: 01246-000 Tel: 3893-4401/4407 E-mail: cep.fm@usp.br

6 - É garantida a liberdade da retirada de consentimento a qualquer momento e deixar de participar do estudo, sem qualquer prejuízo à continuidade de suas atividades curriculares do curso de graduação na Instituição; 7 - Direito de confidencialidade - As informações obtidas serão analisadas em conjunto com as de outros estudantes, não sendo divulgada a identificação de nenhum estudante;

8 - Direito de ser mantido atualizado sobre os resultados parciais das pesquisas, quando em estudos abertos, ou de resultados que sejam do conhecimento dos pesquisadores. O estudante ou seu responsável legal (em caso de estudantes com idade inferior a 18 anos) poderá solicitar, a qualquer momento, quaisquer esclarecimentos e resultados parciais ou que sejam de conhecimento do pesquisador.

9 - Despesas e compensações: não há despesas pessoais para o participante em qualquer fase do estudo. Serão utilizadas salas do bloco didático FOFITO/FMUSP para o desenvolvimento de todas as atividades do projeto, incluindo a sala pró-aluno de graduação.Também não há compensação financeira relacionada à sua participação. Se existir qualquer despesa adicional, ela será absorvida pelo orçamento da pesquisa.

10- Compromisso do pesquisador de utilizar os dados e o material coletado somente para esta pesquisa. Todos os dados obtidos, bem como a identidade de cada participante da pesquisa, serão mantidos em sigilo, sendo que somente a 
ANEXO 2

pesquisadora responsável pelo estudo terá acesso aos dados para análise e discussão.

Acredito ter sido suficientemente informado a respeito das informações que li ou que foram lidas para mim, descrevendo o estudo "Educação mediada por tecnologia em Fonoaudiologia: uma comparação entre três métodos de aprendizagem sobre o Sistema Miofuncional Orofacial".

Eu discuti com a Dra. Claudia Regina Furquim de Andrade sobre a minha decisão em participar nesse estudo. Ficaram claros para mim quais são os propósitos do estudo, os procedimentos a serem realizados, seus desconfortos e riscos, as garantias de confidencialidade e de esclarecimentos permanentes. Ficou claro também que minha participação é isenta de despesas. Concordo voluntariamente em participar deste estudo e poderei retirar o meu consentimento a qualquer momento, antes ou durante 0 mesmo, sem penalidades ou prejuízo ou perda de qualquer benefício que eu possa ter adquirido, ou no meu atendimento neste Serviço.

Assinatura do paciente/representante legal Data

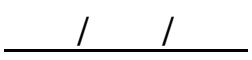

Assinatura da testemunha

Data 11

Para casos de pacientes menores de 18 anos, analfabetos, semi-analfabetos ou portadores de deficiência auditiva ou visual.

(Somente para o responsável do projeto)

Declaro que obtive de forma apropriada e voluntária o Consentimento Livre e Esclarecido deste paciente ou representante legal para a participação neste estudo.

Assinatura do responsável pelo estudo

Data

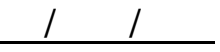


Instructional Material Motivational Survey (IMMS) - Tradução e adaptação

Escala de pontuação:

$1=$ not true $=$ não é verdadeiro

2 =slightly true = ligeiramente verdadeiro

$3=$ moderately true $=$ moderadamente verdadeiro

$4=$ mostly true $=$ em grande parte verdadeiro

$5=$ very true $=$ muito verdadeiro

1. Quando eu olhei pela primeira vez para o material educacional eu tive a impressão de que ele seria fácil para mim.

( ) 1 ( ) 2 ( ) 3 ( )4( ) 5

2. Havia algo interessante no início do material educacional que chamou minha atenção.

( )1 ( )2 ( ) 3 ( )4( )5

3. O material educacional foi mais difícil de entender do que eu gostaria que fosse.

( )1 ( )2 ( ) 3 ( ) $4($ ) 5

4. Depois de ler (ou receber) as informações introdutórias eu me senti confiante de que estava apto a aprender a partir do material educacional

( ) 1 ( ) 2 ( ) 3 ( )4( ) 5

5. Completar os exercícios do material educacional me deu um sentimento de satisfação e realização

( )1 ( ) 2 ( ) 3 ( ) 4 ( ) 5

6. Está claro para mim como o conteúdo do material educacional está relacionado a coisas que eu já sei/conheço

( )1 ( ) 2 ( ) 3 ( ) 4 ( ) 5 
7. Muitas das páginas tem muita informação que foi difícil de captar e se lembrar dos pontos importantes

( )1 ( ) 2 ( ) 3 ( )4( )5

8. O material educacional é atraente

( ) $1($ ) 2 ( ) 3 ( ) $4($ ) 5

9. Havia exemplos que me mostraram como o material educacional pode ser importante para as pessoas que estão aprendendo sobre o Sistema Miofuncional Orofacial

( )1 ( ) 2 ( ) 3 ( ) 4 ( ) 5

10. Completar o material educacional com sucesso foi importante pra mim.

( ) 1 ( ) 2 ( ) 3 ( ) $4($ ) 5

11. A qualidade da escrita ajudou a manter minha atenção.

( ) $1($ ) $2($ ) $3($ ) 4() 5

12. O material educacional é tão abstrato que foi difícil manter minha atenção nele.

( )1 ( )2 ( ) $3($ ) 4() 5

13. Enquanto trabalhava com o material educacional eu estava confiante de que poderia aprender o conteúdo.

( )1 ( ) 2 ( ) 3 ( )4( )5

14. Eu gostei tanto do material educacional que eu gostaria de saber mais sobre o assunto.

( ) 1 ( ) 2 ( ) 3 ( ) $4($ ) 5

15. O design do material educacional parece seco e pouco atraente

( ) 1 ( ) 2 ( ) 3 ( ) 4 ( ) 5

16. O conteúdo do material educacional é relevante para os meus interesses

( )1 ( )2 ( ) 3 ( ) 4 ( ) 5

17. A forma como a informação do material educacional é organizada ajudou a manter minha atenção

( ) 1 ( ) 2 ( ) 3 ( ) $4($ ) 5

18. Há explicações ou exemplos de como as pessoas utilizam o conhecimento no material educacional

( ) 1 ( ) 2 ( ) 3 ( ) 4( ) 5

19. Os exercícios do material educacional eram muito difíceis

( ) 1 ( ) 2 ( ) 3 ( ) 4 ( ) 5

20. O material educacional tem coisas que me interessam

( ) 1 ( ) 2 ( ) 3 ( ) $4($ ) 5

21. Eu realmente gostei de estudar o material educacional

( )1 ( )2 ( )3 ( )4( )5 
22. A quantidade de repetições no material educacional me levou a ficar entediado em algumas vezes

( ) 1 ( ) 2 ( ) 3 ( ) $4($ ) 5

23. O conteúdo e o estilo de escrita no material educacional transmitem a impressão de que vale a pena conhecer seu conteúdo

( ) 1 ( ) 2 ( ) 3 ( ) $4($ ) 5

24. Eu aprendi algumas coisas que foram surpreendentes ou inesperadas

( ) 1 ( ) 2 ( ) 3 ( ) $4($ ) 5

25. Depois de trabalhar no material educacional por um tempo eu estava confiante de que eu seria capaz de passar por um teste sobre o Sistema Miofuncional Orofacial

( )1 ( )2 ( ) 3 ( ) $4($ ) 5

26. O material educacional não foi relevante para minhas necessidades porque eu já sabia a maior parte dele

( ) 1 ( ) 2 ( ) 3 ( ) $4($ ) 5

27. O trabalho com feedback após os exercícios ou outros comentários no material educacional me ajudou-me a sentir recompensado pelo meu esforço

( ) 1 ( ) 2 ( ) 3 ( ) $4($ ) 5

28. A variedade das passagens escritas, exercícios, ilustrações etc., ajudaram a manter minha atenção no material educacional

( ) 1 ( ) 2 ( ) 3 ( ) $4($ ) 5

29. $O$ estilo de escrita é chato

( ) 1 ( ) 2 ( ) 3 ( ) 4 ( ) 5

30. Eu poderia relacionar o conteúdo do material educacional a coisas que eu tenho visto, feito ou pensado a respeito em minha vida

( ) 1 ( ) 2 ( ) 3 ( ) $4($ ) 5

31. Há tantas palavras em cada janela que é irritante

( ) $1(1) 2() 3() 4() 5$

32. Eu me senti bem em terminar o material educacional

( ) $1($ ) $2($ ) $3($ ) 4() 5

33. O conteúdo do material educacional é útil para mim

( ) 1 ( ) 2 ( ) $3($ ) 4() 5

34. Eu não conseguia realmente entender um pouco do material educacional

( ) 1 ( ) 2 ( ) 3 ( ) 4 ( ) 5

35. A boa organização do conteúdo me ajudou a ter certeza de que eu aprenderia este material

( ) $1(1) 2() 3() 4() 5$

36. Foi um prazer trabalhar em um material tão bem concebido/desenhado

( )1 ( )2 ( ) 3 ( ) 4( )5 


\section{REFERÊNCIAS}

1. Zemlin, WR. Princípios de anatomia e fisiologia em Fonoaudiologia. Porto Alegre: Artmed, 2000.

2. Felício CM. Desenvolvimento normal das funções estomatognáticas. In: Ferreira, LP; Befi-Lopes, DM; Limongi, SCO (org.). Tratado de Fonoaudiologia. São Paulo: Roca, 2004. p.195.

3. Yuen HK, Fallis M, Martin-Harris B. A survey of head and neck cancer curriculum in United States speech language pathology masters programs. $J$ Cancer Educ. 2010 Dec;25(4):556-9.

4. Paalman $\mathrm{MH}$. Why teach anatomy? Anatomists respond. The Anatomic Record (New Anat.). 2000;261:1-2.

5. Anderson, J; DiCarlo, SE. "Virtual" experiment for understanding the eletrocardiogram and the mean eletrical axis. Adv Physiol Educ. 2000;23:1-17.

6. Goldberg, HR; McKhann, GM. Student test scores are improved in a virtual learning environment. Adv Physiol Educ. 2000;23:59-66.

7. Ohrn, MAK et al. A comparison of tradicional textbook and interactive computer learning of neuromuscular block. Anesth Analg. 1997;84(3):657-661.

8. Fang TY, Wang PC, Liu CH et al. Evaluation of a haptics-based virtual reality temporal bone simulator for anatomy and surgery training. Computer Methods Programs Biomed. 2014;113:674-681. 


\section{REFERÊNCIAS}

9. Longmuir KJ. Interactive computer-assisted instruction in acid-base physiology for mobile computer platforms. Adv Physiol Educ. 2014;38:34-41.

10. Smetana LK, Bell RL. Computer simulations to support science instruction and learning: a critic review of literature. Int J Sci Educ. 2012:34(9):1337-1370.

11. Sweller J. Cognitive load during problem solving: Effects on learning. Cognitive Sci. 1988;12:257-285.

12. Sweller J, van Merriënboer JJG,Paas FGWC. Cognitive architecture and instructional design. Educ Psychol Rev. 1998; 10(3):251-296.

13. Rummel, N; Spada, H. Learning to collaborate: an instruction approach to promoting collaborative problem solving in computer-mediated settings. J Learn Sci. 2005;14(2):201-241.

14. Pearson, J. Investigating ICT using problem-based learning in face-to-face and online learning environments. Comput Educ. 2006;47(1):56-73.

15. Kester, L; Lehnen, C; Van Gerven, PWM; Kirschner, PA. Just-in-time schematic supportive information presentation during cognitive skill acquisition. Comput Hum Behav. 2006;22(1):93-116.

16. Silva, AS; Delacruz, GC. Hybrid reality games reframed - potential uses in educational contexts. Games Cult. 2006;1(3):231-251.

17. Thomas, D; Brown, JS. The play of imagination - Extending the literary mind. Games Cult. 2007;2(2):149-172. 
REFERÊNCIAS

18. Ebner M, Holzinger A. Successful implementation of user-centered game based learning in higher education: An example from civil engineering. Comput Educ. 2007;49:873-890.

19. Prensky M. Digital Game-Based Learning. New York: McGraw-Hill, 2001.

20. Gee, JP. Good vídeo games and good learning: collected essays in video games, learning and literacy. Peter Lang Publishing: New York, 2007.

21. Kalyuga S. Instructional design for the development of transferable knowledge and skills: A cognitive load perspective. Comput Hum Behav. 2009;25:332-338.

22. Huang WH. Evaluating learners' motivational and cognitive processing in an online game-based learning environment. Comput Hum Behav. 2011;27:694704.

23. Hong J-C, Cheng C-L, Hwang M-Y, Lee C-K e Chang H-Y. Assessing the educational values of digital games. J Comput Assist Lear. 2009;25:423-437.

24. Driskell JE, Willis RP, Cooper C. Effect of over-learning on retention. J Appl Psychol. 1992;77:615-622.

25. Walliser B. A spectrum of equilibration processes in games. J Evol Econ. 1998;8:67-87.

26. Coyne R. Mindless repetition: learning from computer games. Des stud. 2003;24:199-212. 


\section{REFERÊNCIAS}

27. Shaffer, D. W., Squire, K. R., Halverson, R., \& Gee, J. P. Video games and the future of learning [Versão Eletrônica], 21, 2004. Acesso em: 20 de Março de 2014.

Disponível

em:

http://www.academiccolab.org/resources/gappspaper1.pdf.

28. Liu C-C, Cheng Y-B, Tsai C-C, Huang C-C. The effect of simulation games on the learning of computacional problem-solving. Comput Educ. 2011;57(3):1907-1918.

29. Kim S, Chang MD. Computer Games for the Math Achievement of Diverse Students. J Educ Technol Soc. 2010;13( 3): 224-232.

30. Akl et al. The effect of educational games on medical students' learning outcomes: A systematic review: BEME Guide No 14. Med Teach.2010;32:1627.

31. Boreham N, Foster R, Mawer G. The phenytoin game: Its effect on decision skills. Simulat Games. 1989;20(3):292-299.32.

32. Chui C, Ong JSK, Lian Z-Y, et al. Haptics in computer-mediated simulation: training in vertebroplasty surgery. Simulat Gaming. 2006;37(4):438-51.

33. Bie MH, Lipman LJA. The Use of Digital Games and Simulators in Veterinary Education: An overview with Examples. JVME. 2012;39(1):13-20.

34. Gallagher AG, Ritter EM, Champion $\mathrm{H}$, et al. Virtual reality simulation for the operating room: proficiency-based training as a paradigm shift in surgical skills training. Ann Surg. 2005;241(2):364-72. 


\section{REFERÊNCIAS}

35. Lin DW, Romanelli JR, Kuhn JN, et al. Computer-based laparoscopic and robotic surgical simulators: performance characteristics and perceptions of new users. Surg Endosc. 2009;23(1):209-14.

36. Rondon S, Sassi FC, Andrade CRF. Computer game-based and traditional learning method: a comparison regarding students' knowledge retention. BMC Med Educ. 2013;30:1-8.

37. Kanthan R,Senger JL.The impact of specially designed digital game-based learning inundergraduate pathology and medical education. Arch Pathol and Lab Med. 2011;135:135-14236.

38. Selby G, Walker V, Diwkar V. A comparison of teaching methods: interactive lecture versus game playing. Med Teach. 2007;29:972-974.

39. Zhang BH, Liu X, Krajcik S. Expert models and modeling processes associated with a computer-modeling tool. Sci Educ. 2006;90:579-604.

40. Barak M, Hussein-Farraj R. Integrating model-based learning and animations for enhancing students' understanding of proteins structure and function. Res Sci Educ. 2013;43:619-636.

41. Yarden $\mathrm{H}$, Yarden A. Learning using dynamic and static visualizations: students' comprehension, prior knowledge and conceptual status of a biotechnological method. Res Sci Educ. 2010;40(3):375-402. 


\section{REFERÊNCIAS}

42. Barak M, Ashkar T, Dori YJ. Learning science via animated movies: its effect on students' thinking and motivation. Comput Educ. 2011;56:839-846.

43. Ramasundarm V, Grunwald S, Mangeot A, Comeford NB, Bliss CM. Development of an environmental virtual field laboratory. Computers. 2005;45:21-34.

44. Rieber L, Kini A. Theoretical foundations of instructional applications of computer generated animated visuals. J Comput-Base Instr. 1991;18(3):83-88.

45. Hoffler TN, Leutner D. Instructional animations versus static pictures: a meta-analysis. Learn Instr. 2007;17(6):722-738.

46. Garcia RR, Quiros OJ, Gallego SR, Martin GR, Fernanz SM. Interactive multimídia animation with macromedia flash in descriptive geometry teaching. Comput Educ. 2007;49(3):615-639.

47. Clements DN, Broadhurst H, Clarke SP, Farell M, Bennett D, Mosley JR, Mellanby RJ. The effectiveness of 3D animations to enhance understanding of cranial cruciate ligament rupture. JVME. 2013;40(1):29-34.

48. Tatcher JD. Computer animation and improved student comprehension of basic science concepts. JAOA. 2006;106(1):9-14.

49. Vieira MMRM, Berretin-Felix G, BrasolottoAG.The Virtual Man Project's CDROM "Voice Assessment: Speech-Language Pathology and Audiology \& Medicine", Vol.1. J Appl Oral Sci. 2009;17(sp. Issue):43-49. 


\section{REFERÊNCIAS}

50. Venail F, Deveze A, Lallemant B, Guevara N, Mondain M. Enhancement of temporal bone anatomy learning with computer 3D rendered imaging software. Med Teach. 2010;32:e282-e288.

51. Kalet AL, Song HS, Sarpel U, Schwartz R, Brenner J, Ark TK, Plass J. Just enough, but not too much interactivity leads to better clinical skills performance after a computer-assisted learning module. Med Teach. 2012;34:833-839.

52. Keegan RD, Brown GR, Gordon A. Use of simulation of the ventilatorpatient interaction as an active learning exercise: comparison with traditional lecture. JVME. 2012;39(4):359-367.

53. Bloomfield, J., Roberts, J., While, A. The effect of computer-assisted learning versus conventional teaching methods on the acquisition and retention of handwashing theory and skills in pre-qualification nursing students: A randomized controlled trial. Int J Nurs Stud. 2010;47:287-294.

54. Fang TY, Wang PC, Liu CH, Su MU, Yeh SC. Evaluation of a haptics-based virtual reality temporal bone simulator for anatomy and surgery training. Comput Methods Programs Biomed. 2014;113(2):674-681.

55. Macbean N, Theodoros D, Davison B, Hill AE. Simulated learning environments in speech-language pathology: an Australian response. Int J Speech Lang Pathol. 2013;15(3):345-357. 


\section{REFERÊNCIAS}

56. Hill AE, Davison BJ, Theodoros DG. A review of standardized patients in clinical education: implications for speech-language pathology programs. Int J Speech Lang Pathol.. 2010;12:259-270.

57. Bressman T, Eriks-Bruphy A. Use of simulated patients for a student learning experience on managing difficult patient behavior in speech-language pathology contexts. Int J Speech Lang Pathol. 2012;14(2):165-173.

58. Zraick R. Review of the use of standardized patients in speech-language pathology clinical education. Int J Ther Rehabil. 2012;19:112-118.

59. Williams S, Schreiber LR. Beyond the big screen: avatars prepare graduate students for real-word practice. Perspect School-Based Issues J. 2010;11:5055.

60. Ward EC, Baker SC, Wall LR, Duggan BL, Hancock KL, Bassett LV, Hyde TJ. Can human mannequin-based simulation provide a feasible and clinically acceptable method for training tracheostomy management skills for speechlanguage pathologists? Am J Speech-Lang Pat. 2014;23(421-436).

61. Watson K, Wright A, Morris N, McMeeken J, Rivett D, Blackstock F et al. Can simulation replace part of clinical time? Two parallel randomised controlled trials. Med Educ. 2012;46:657-667. 


\section{REFERÊNCIAS}

62. Hill AE, Davidson BJ, McAllister S, Wright J, Theodoros DG. Assessment of student competency in a simulated speech-language pathology clinical placement. Int J Speech Lang Pathol. 2014;16(5):464-75.

63. Ebner M, Holzinger A. Successful implementation of user-centered game based learning in higher education: An example from civil engineering. Comput Educ. 2007;49:873-890.

64. Di Serio A, Ibáñez MB, Kloss CD. Impact of an augmented reality system on students' motivation for a visual art course. Comput Educ. 2013;68:586-596.

65. Hong J-C, Cheng C-L, Hwang M-Y, Lee C-K e Chang H-Y. Assessing the educational values of digital games. J Comput Assist Lear. 2009;25:423-437.

66. Rost M. Generating student motivation. [Internet]. WorldView, Pearson Longman. 2006. Acesso em: 20 de Março de 2014. Disponível em: http://www.longmanhomeusa.com/content/WorldView_Motivation.pdf

67. Liu C-C, Cheng Y-B, Tsai C-C, Huang C-C. The effect of simulation games on the learning of computacional problem-solving. Comput Educ. $2011 ; 57(3): 1907-1918$.

68. Kebritchi M, Hirumi A, Bai $\mathrm{H}$. The effects of modern mathematics computer games on mathematics achievement and class motivation. Comput Educ. 2010;55:427-443. 
REFERÊNCIAS

69. Chen MP, Wong YT, Wang LC. Effects of type of exploratory strategy and prior knowledge on middle school students' learning of chemical formulas from a 3D role-playing game. Education Tech Research Dev. 2014;62:163-185.

70. Avargil S, Herscovitz O, Dori YJ. Teaching thinking skills in context-based learning: teacher's challenges and assessment knowlege. J Sci Educ Technol. 2012;21:207-225.

71. Sachs J. A path model for adult learner feedback. Educ Psychol. 2001;21: $267-275$.

72. Huang WH. Evaluating learners' motivational and cognitive processing in an online game-based learning environment. Comput Hum Behav. 2011;27:694704.

73. Shen J, Eder LB. Intentions to use virtual worlds for education. J Inform Syst Educ. 2009;20(2):225-233.

74. Huang H M, Rauch U, Liaw SS. Investigating learners' attitudes toward virtual reality learning environments: Based on a constructivist approach. Comput Educ. 2010: 55(3):1171-1182.

75. Harder BN. Use of simulation in teaching and learning in health sciences: a systematic review. J Nurse Educ. 2010;49(1):23-28.

76. Huang W, Huang W, Diefes-Dux H, Imbrie PK. A preliminar validation of Attention, Relevance, Confidence and Satisfaction model-based Instructional 
Material Motivational Survey in a computer-based tutorial setting. British J Educ Technol. 2006;37(2):243-259.

77. Huang $\mathrm{W}-\mathrm{H}$, Huang $\mathrm{W}-\mathrm{Y}$ e Tschopp J. Sustaining iterative game playing processes in DGBL: The relationship between motivational processing and outcome processing. Comput Educ. 2010;55:789-797.

78. Keller JM. Strategies for stimulating the motivation to learn. Perform Instruct. 1987a;26:1-7.

79. Keller JM. The systematic process of motivational design. Perform Instruct. 1987b;29(9/10):1-8.

80. Small RV. Motivation in instructional design. Teach Librarian. 2000;27:2931.

81. Song SH, Keller JM. Effectiveness of motivationally adaptive computerassisted instruction on the dynamic aspects of motivation. Educ Technol Res Dev. 2001;49(2):5-22.

82. Keller JM. An integrative theory of motivation, volition and performance. Technol Instruct Cognition Lear. 2008; 6:79-104.

83. Hanus MD, Fox J. Assessing the effects of gamification in the classroom: a longitudinal study of intrinsic motivation, social comparison, satisfaction, effort, and academic performance. Comput Educ. 2015;80:152-161 . 


\section{REFERÊNCIAS}

84. Likert R. A technique for the measurement of attitudes. Arch Psychol. 1932;140:1-55.

85. Kovacevic I, Minovic M, Milovanovic M, de Pablos PO, Starcevic D. Motivational aspects of different learning contexts: "My mom won't let me play this game...". Comput Hum Behav. 2013;29:354-363.

86. Novak E. Toward a mathematical model of motivation, volition and performance. Comput Educ. 2014;74:73-80.

87. Sung HY, Hwang GJ, Yen YF. Development of a contextual decisionmaking game for improving student's learning performance in a health education course. Comput Educ. 2015;82:179-190.

88. Loorbach N, Peters O, Karreman J, Steehouder M. Validation of the Instructional Materials Motivation Survey (IMMS) in a self-directed instructional setting aimed at working with technology. British J Educ Technol.. 2015;46(1):204-218.

89. Cook DA, Beckman TJ, Thomas KG. Measuring motivational characteristics of courses: applying Keller's Instructional Materials Motivation Survey to a webbased course. Acad Med. 2009;84(11):1505-1509.

90. Jang KS, Park OJ, Hong MS, et al. A study on development of web-based learning program with multimedia ECG monitoring and its application. $J$ Korean Soc Med Inform. 2003;9:101-110. 


\section{REFERÊNCIAS}

91. Jang KS, Hwang SY, Park SJ, Kim YM, Kim MJ. Effects of a web-based teaching method on undergraduate nursing students' learning of electrocardiography. J Nurs Educ. 2005;44:35-39.

92. Seikel JA, King DW, Drumright DG. Anatesse 2.0: Eletronic classroom manager to accompany Anatomy and Phisyology for Speech, Language and Hearing. CD-ROM. In: Anatomy and Phisyology for Speech, Language and Hearing. USA: Thomas Delmar Learning. 3rd edition, 2005.

93. Primal Pictures: interactive system anatomy, interactive regional anatomy, surgical and functional and the 3D real-time body. Acesso em: 20 de Março de 2014. Disponível em: http://www.anatomy.tv

94. Felício CM, Folha GA, Ferreira CLP, Medeiros APM. Expanded protocol of orofacial myofunctional evaluation with scores: validity and reliability. Int $J$ Pediatr Otorhi. 2010;74:1230-1239.

95. Chang M, Lehman JD. Learning foreign language through an interactive multimedia program: an experimental study on the effects of the relevance component of the ARCS model. CALICO Journal. 2002;20: 81-98.

96. Cook DA, Levinson AJ, Garside S. Time and learning efficiency in internetbased learning: a systematic review and meta-analysis. Adv Health Sci Educ. 2010b;15(5):755-770. 


\section{REFERÊNCIAS}

97. Draycott TJ, Crofts JF, Ash JP, Wilson LV, Yard E, Sibanda T, Withlaw A. Improving neonatal outcome through practical shoulder dystocia training. Obstet Gynecol. 2008;112:14-20.

98. McGaguie WC, Issenberg SB, Cohen ER, Barsuk JH, Wayne DB. Does simulation-based medical education with deliberate practice yield better results than traditional clinical education? A meta-analytic comparative review of the evidence. Acad Med. $2011 ; 86: 706-711$.

99. Bastos LF, van Meurs W, Ayres-de-Campos D. A model for educational simulation of the evolution of uterine contractions during labor. Comput Methods Programs Biomed. 2012;107:242-247.

100. Torrente J, Borro-Escribano B, Freire M, del Blanco A, Marchiori EJ, Martínez-Ortiz I, et al. Development of game-like simulations for procedural knowledge in healthcare education. IEEE T LearnTechnol. 2014;7(1):69-82.

101. Schweppe J, Rummer R. Attention, working memory and long-term memory in multimedia learning: an integrated perspective based on process models of working memory. Educ Psychol Rev. 2014;26:285-306.

102. Schroff RH, Vogel DR, Coombes J, Lee F. Student e-learning intrinsic motivation: a qualitative analysis. Commun Assoc Inform Syst. 2007;19:241260. 
103. Walker JD, Cotner SH, Baepler PM et al. A delicate balance: integrating active learning into a large lecture course. CBE Life Sci Educ. 2008;7(4):361367.

104. Balci S, Cakiroglu J, Tekkaya C. Engagement, exploration, explanation, extension and evaluation (5E): learning cycle and conceptual change text as learning tools. Biochem Mol Biol Educ. 2006;34(3):199-203.

105. Barko T, Sadler TD. Practicality in virtuality: finding student meaning in video-game education. J Sci Educ Technol. 2013;22(2):124-132.

106. Skuballa I, Schwonke R, Renkl A. Learning from narrated animations with different support procedures: working memory capacity matters. Appl Cognitive Psych. 2012;26:840-847.

107. Ryan RM, Decy EL. Self-determination theory and facilitation of intrinsic motivation, social development, and well-being. Am Psychol. 2000;55(1):68-78.

108. Cheng YC, Yeh HT. From concepts of motivation to its application in instructional design: reconsidering motivation from an instructional design perspective. British J Educ Technol. 2009;40:597-605.

109. Pellas N, Kazanidis I. Engaging students in blended and online collaborative courses at university level through Second Life: comparative perspectives and instructional affordances. New Rev Hypermedia M. 2014;20(2):123-144. 